\title{
Resiliência do volume de madeira de espécies comerciais em diferentes áreas experimentais na Amazônia Oriental
}

O objetivo do estudo é avaliar o comportamento do volume de madeira em diferentes grupos de espécies arbóreas comercias ao longo do tempo em áreas experimentais na Amazônia Oriental Brasileira. Foram analisada a dinâmica do volume na Flona Tapajós, Floresta Monte Dourado-Jari, Floresta do Moju e Fazenda Rio Capim. Foram realizados inventários florestais de espécies arbóreas a partir de $20 \mathrm{~cm}$ diâmetro. Esses inventários foram realizados em diferentes anos antes e após a exploração florestal em cada área experimental. Para análise dos dados foram para as classes de diâmetro entre 20 e $49,9 \mathrm{~cm}$, para caracterizar o estoque de madeira reservado para a futura exploração, e outra classe com árvores de DAP $\geq 50 \mathrm{~cm}$ para caracterizar o volume da presente colheita. Foram calculados os equações do volume. As categorias de grupos de espécies arbóreas comerciais foram G1, G2, G3, G4 e G5 e essa classificação foram realizadas através das espécies arbóreas comerciais encontradas nas áreas estudos comparadas com as espécies arbóreas comerciais encontradas em Pará (2016). Os volumes foram por categorias de grupos de espécies arbóreas comercias ao longo do tempo, tratamentos silviculturais e classe diamétrica. Os resultados encontrados variaram de acordo com tratamentos silviculturais, classe diamétrica e períodos. Através do estudo é possível afirmar que a floresta é capaz de ter sua resiliência volumétrica, pois se observou nessas áreas de estudos, que a maioria das espécies arbóreas comerciais nos diferentes tratamentos silviculturais aumentaram seu volume após 30, 26 e18 anos de exploração florestal de impacto reduzido.

Palavras-chave: Exploração de impacto reduzido; Florestas de terra firme; Tratamentos silviculturais.

\section{Resilience of wood volume of commercial species in different experimental areas in the Eastern Amazon}

\begin{abstract}
The aim of this study is to evaluate the behavior of wood volume in different groups of commercial tree species over time in experimental areas in the Brazilian Eastern Amazon. Volume dynamics were analyzed at Flona Tapajós, Monte Dourado-Jari Forest, Moju Forest and Rio Capim Farm. Forest inventories of tree species from $20 \mathrm{~cm}$ diameter were carried out. These inventories were carried out at different years before and after logging in each experimental area. Data were analyzed for diameter classes between 20 and $49.9 \mathrm{~cm}$, to characterize the wood stock reserved for future exploration, and another class with DBH trees $\geq 50 \mathrm{~cm}$ to characterize the volume of the present harvest. Volume equations were calculated. The categories of commercial tree species groups were G1, G2, G3, G4 and G5 and this classification was performed by the commercial tree species found in the study areas compared to the commercial tree species found in Pará (2016). The volumes were by categories of commercial tree species groups over time, silvicultural treatments and diameter class. The results found varied according to silvicultural treatments, diameter class and periods. Through the study it is possible to affirm that the forest is capable of having its volumetric resilience, since it was observed in these study areas that most commercial tree species in different silvicultural treatments increased their volume after 30,26 and 18 years of reduced impact logging.
\end{abstract}

Keywords: Low impact exploitation; Dryland forests; Silvicultural treatments.

Topic: Ciências Florestais

Reviewed anonymously in the process of blind peer

Francimary da Silva Carneiro (D)

Embrapa Amazônia Oriental, Brasil

http://lattes.cnpq.br/8657235544233319

http://orcid.org/0000-0002-1693-8779

francimarycarneiro@gmail.com

Ademir Roberto Ruschel (iD)

Embrapa Amazônia Oriental, Brasil

http://lattes.cnpq.br/6636714035510120

http://orcid.org/0000-0002-0352-5238

ademir.ruschel@embrapa.br

Lucas José Mazzei de Freitas (iD)

Embrapa Amazônia Oriental, Brasil

http://lattes.cnpq.br/5795318631773924

http://orcid.org/0000-0002-1757-9472

lucas.mazzei@embrapa.br
Received: 02/10/2019

Approved: 26/11/2019

\author{
Klewton Adriano Oliveira Pinheiro (it) \\ Instituto Federal do Pará, Brasil \\ http://lattes.cnpq.br/8139678842009696 \\ http://orcid.org/0000-0003-2696-4249 \\ klewton.pinheiro@gmail.com \\ Larissa Martins Barbosa D'Arace (iD \\ Embrapa Amazônia Oriental, Brasil \\ http://lattes.cnpq.br/1315133297466306 \\ http://orcid.org/0000-0002-8533-555X \\ larissamartins350@gmail.com

\section{Mayra Piloni Maestri (iD} \\ Universidade Federal Rural da Amazônia, Brasil \\ http://lattes.cnpq.br/2687102042811310 \\ http://orcid.org/0000-0002-8936-952X \\ mayrapmaestri@hotmail.com
}

Referencing this:

CARNEIRO, F. S.; RUSCHEL, A. R.; FREITAS, L. J. M.; PINHEIRO, K. A. O.; D'ARACE, L. M. B.; MAESTRI, M. P.. Resiliência do volume de madeira de espécies comerciais em diferentes áreas experimentais na Amazônia Oriental. Revista Ibero Americana de Ciências Ambientais, v.10, n.6, p.15-31, 2019. DOI: http://doi.org/10.6008/CBPC2179$\underline{6858.2019 .006 .0003}$ 


\section{INTRODUÇÃO}

As florestas tropicais apresentam uma diversidade florística incalculável, e as espécies que a compõem, apresentam uma dinâmica florestal que é o recrutamento, crescimento, sobrevivencia e mortalidade, isso influência a sua estrutura horizontal e vertical ou seja sua abuância, frequência, volume, distribuição diamétrica etc.. Após essas florestas passarem por uma exploração de impacto reduzido, as mesmas, ao longo do tempo, são capazes de retornar ao seu estado natural e manter seu estoque volumetrico e consquentemente a sua resiliencia em volume de madeira. No entatanto essa exploração deve ser através de um plano de manejo florestal, para minimizar os impactos da exploração na área e manter a diversidade florística entre outros.

A madeira das florestas tropicais tem grandes utilidades nas indústrias de movelaria, para construções civis, navais, energia, entre outros. A exploração florestal ilegal ou a exploração tradicional, consiste em explorar a floresta sem planejamento, a qual não visa a sustentabilidade da mesma, e sim a extração de árvores com grande valor no mercado, sem se importar coma as árvores remanescentes , com a degradação do solo, diversidade florística, além de não favorecer a resiliência florestal entre outros prejuízos econômicos, sociais e ambientais.

Através de estudos realizados ao longo de décadas desenvolveu-se as técnicas de manejo florestal, a qual chamamos de exploração de impacto reduzido, que visa a sustentabilidade da floresta. As técnicas de manejo florestal consiste de planejamento antes, durante e após a exploração, através de inventários florestais, são aplicados tratamentos silviculturais, confecção de mapas, o planejamento e a exploração é realizado por uma equipe de profissionais capacitados.

Devido a importância dos serviços ecossistêmicos oferecidos pela floresta para a vida e também sua utilidade para o setor madeireiro, o meio cientifico busca sempre equilibrar esse contexto, elucidando algumas características da floresta antes e pós colheita para um melhor uso deste ecossistema (SILVA, 2004; OLIVEIRA, 2005).

Durante a década de 70 foram feitas as primeiras explorações planejadas e mecanizadas na Amazônia oriental Brasileira, onde todas as árvores comerciais com DAP maior que $45 \mathrm{~cm}$ de diâmetro eram colhidas, essas explorações serviram para motivar os experimentos da Embrapa Amazônia oriental em duas áreas florestais durante a década de 80, uma no Km 114 (1982) no estado do Pará e outra na Floresta do Jari (1984) no estado do Amapá, onde foram utilizados vários tratamentos incluindo diferentes intensidade de corte, variedade de diâmetros, diferentes áreas basais e diferentes tratamentos silviculturais. Com os resultados do monitoramento dessas áreas foi feita outra exploração experimental na década de 90 no município de Moju sem tratamentos e outra na década de 2000 no município de Paragominas com tratamentos pós colheita, ambas no estado do Pará.

Após a extração de madeira é importante estudos da dinâmica da floresta a fim de avaliar os impactos causados pela mesma, bem como para acompanhar o processo de restabelecimento da floresta (CASTRO et al., 2014), sendo fundamentais para embasar qualquer iniciativa de preservação e conservação dos 
remanescentes florestais (RÊEG et al., 2015). Os resultados desses monitoramentos continuo contribuíram para a atual legislação florestal Brasileira, a qual prioriza a exploração de impacto reduzido e o manejo florestal sustentável.

Uma recomendação de práticas de manejo sustentável, para a floresta amazônica, requer uma melhor compreensão dos impactos a longo prazo em toda a região (SILVA et al., 1995; CARVALHO et al., 2004). Definir modalidades e intensidades de corte em função das características regionais da floresta amazônica constitui um desafio, devido a dificuldade de acesso a informação de vários sitios para representar a região. Com isso o obejtivo do estudo é avaliar o comportamento do volume de madeira em diferentes grupos de espécies arbóreas comercias ao longo do tempo em áreas experimentais na Amazônia Oriental Brasileira.

\section{MATERIAIS E MÉTODOS}

\section{Áreas de estudo}

Os dados foram coletados em quatro áreas distribuídas na Amazônia Oriental Brasileira, uma localizada no estado do Amapá, município de Vitória do Jari, na linha que limita esse estado ao estado do Pará. As outras três áreas estão no estado do Pará, sendo uma a oeste Flona Km 114, outra no nordeste Moju e outra no sudeste Peteco desta região.

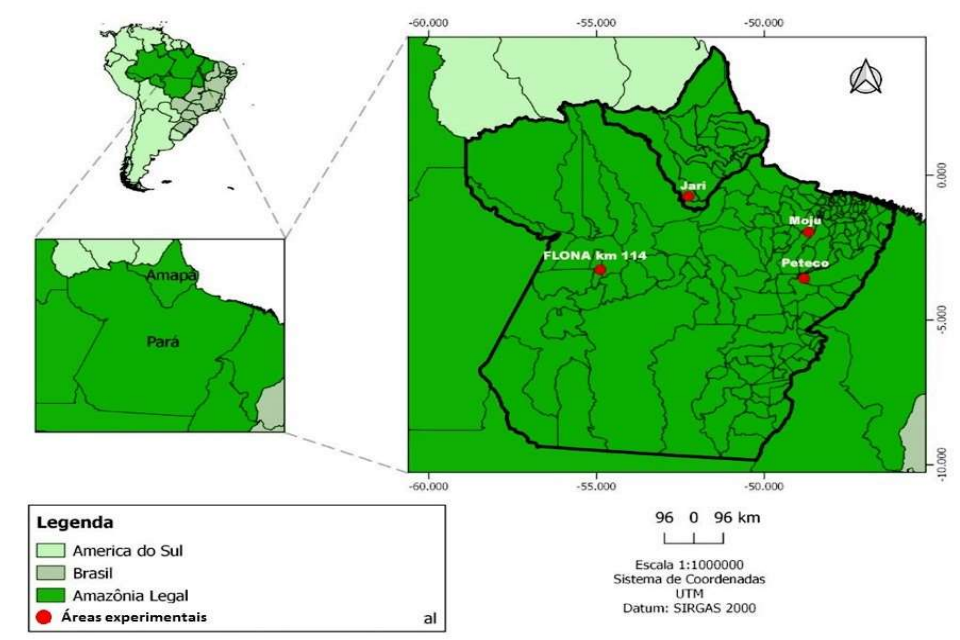

Figura 1: Mapa de localização das áreas experimentais.

\section{Flona do Tapajós}

Esta área está localizada na Floresta Nacional do Tapajós, as proximidades do km 114 da BR 163, Rodovia Santarém-Cuiabá, entre as coordenadas $2^{\circ}=40^{\prime}-4^{\circ} 10^{\prime}$ de Latitude Sul e $54 \circ 4^{\circ} 5^{\prime}-55^{\circ} 30^{\prime}$ de Longitude Oeste no estado do Pará. A topografia da região é plana a ligeiramente ondulada e a altitude é de cerca de 175 m acima do nível do mar. O clima da região é tropical úmido, do tipo Ami com temperatura média anual de $25,5^{\circ} \mathrm{C}$ e umidade relativa média de $90 \%$ de acordo com a classificação de Köppen (ALVARES et al., 2013). Nessa região, há predominância de Latossolo Amarelo Distrófico, perfil profundo e baixa fertilidade, caracterizados por textura muito argilosa, e revestido por florestas densas. A vegetação da área de estudo é 
classificada como Floresta Ombrófila Densa, caracterizando-se por indivíduos arbóreos de grande porte e pela presença de lianas lenhosas, palmeiras e epífitas emergentes e cobertura arbórea uniforme (IBGE, 2012; IVANAUSKAS et al., 2012).

\section{Companhia Florestal Monte Dourado- Jari}

Esta área Experimental está delimitada em uma área de 500 ha de floresta densa na Companhia Florestal Monte Dourado, na localidade Morro do Felipe, município de Vitória do Jari, no estado do Amapá. A tipologia florestal é Floresta Ombrófila Densa. As coordenadas geográficas é $52^{\circ} 20^{\prime \prime} \mathrm{W}$ e $00^{\circ} 55^{\prime \prime} \mathrm{S}$. O clima é Am. Temperatura é $25,8^{\circ} \mathrm{C}$, a topografia é plano levemente ondulado, o tipo de solo é latossolo amarelo distrófico com textura argilosa pesada.

\section{Floresta do Moju}

Essa área está localizada no município de Moju, no estado do Pará, com uma área total de 1.050 há de floresta, situado entre as coordenadas geográficas $02^{\circ} 08^{\prime} 14^{\prime \prime}$ e $02^{\circ}$ 12' $26^{\prime \prime}$ de latitude Sul e entre $48^{\circ}$ 47' 34" e 48 48' 14" de longitude a Oeste de Greenwich, entre o km 30 da Rodovia PA-150 e o Rio Ubá. O clima da região é do tipo Am, segundo a classificação de Köppen. A precipitação pluviométrica anual varia de 2.000 a $3.000 \mathrm{~mm}$, distribuída irregularmente, tendo pequenos períodos secos, sendo o período mais chuvoso entre os meses de fevereiro e abril, e o mais seco de agosto a outubro. A umidade relativa do ar em torno de $85 \%$. A temperatura média anual é de 26 으, o relevo da área experimental é plano, com pequenas ondulações, com declives de até 3\%. Predomina na área o Latossolo Amarelo distrófico com diferentes texturas ocorrendo também solos Podzólicos Vermelhos-amarelos, Glei pouco úmido e plinto solo. A tipologia florestal da área experimental é Floresta Ombrófila Densa de terra firme. Possui árvores com o porte variando entre 25 a $35 \mathrm{~m}$ de altura com presença de algumas palmeiras no sub-bosque (LOPES et al., 2001; SILVA et al., 2001).

\section{PETECO na fazenda Rio capim}

A área está localizada na fazenda Rio Capim $\left(3^{\circ} 30^{\prime}\right.$ e $3^{\circ} 45^{\prime}$ de latitude Sul e $48^{\circ} 30^{\prime}$ e $48^{\circ} 45^{\prime}$ de longitude Oeste), de propriedade da empresa Cikel Brasil Verde Madeiras Ltda., no município de Paragominas, no estado do Pará. A tipologia florestal é Floresta Ombrófila Densa. O clima é Aw, a temperatura é em torno de $27,2^{\circ} \mathrm{C}$, a topografia é plano levemente ondulado e o tipo de solo predominante é o Latossolo amarelo.

\section{Delineamento experimental}

\section{Flona Tapajós}

Em 1981, foi implantado o experimento com um censo florestal e utilizando o delineamento de blocos ao acaso (DBC) com quatro repetições e quatro tratamentos (Tabela 1), totalizando 144 ha de área, 
sendo instaladas 48 parcelas permanentes retangulares de 0,25 ha cada, ao mesmo tempo houve o corte de lianas. Em 1982 houve a exploração florestal, com a retirada de $73 \mathrm{~m}^{3} \cdot \mathrm{ha}^{-1}$, em média 12,5 árvores.ha-1 pertencentes a 38 espécies comerciais na época. Em 1983 em um bloco de 36 ha foi adicionado o tratamento T0, representado pela floresta sem nenhuma intervenção. Em 1994, doze anos após a exploração florestal, foram aplicados os tratamentos silviculturais, eliminando árvores de espécies não comerciais na época, com a finalidade de reduzir a área basal do povoamento e, com isso, reduzir a competição entre árvores por luz, espaço e nutrientes, proporcionando o aumento da sobrevivência, crescimento e estabelecimento da regeneração natural das espécies de valor comercial (OLIVEIRA et al., 2005). No final do ano de 1996 até o início de 1997, houve um incêndio na área, atingindo 19 das 60 parcelas instaladas, sendo seis parcelas do tratamento TO (1,5ha), duas do tratamento T1 (0,5ha), cinco do tratamento T2 $(1,25 \mathrm{ha})$ e seis do tratamento T4 (1,5ha), essas parcelas foram utilizadas neste estudo.

Tabela 1: Tratamentos utilizados na Flona do Tapajós.

\begin{tabular}{|c|c|c|}
\hline $\begin{array}{l}\text { Tratamento } \\
\text { Silvicultural }\end{array}$ & Ano & Descrição dos Tratamentos Silviculturais \\
\hline \multirow[t]{2}{*}{ TO } & 1983 & Instalação do tratamento sem nenhuma intervenção humana \\
\hline & 1996 & Fogo acidental atingindo metade das parcelas do tratamento \\
\hline \multirow[t]{2}{*}{$\mathrm{T} 1$} & 1982 & $\begin{array}{l}\text { Colheita de árvores com DAP } \geq 45 \mathrm{~cm} \text {, este tratamento reduziu a área basal em torno de } 24 \% \text { do } \\
\text { original. }\end{array}$ \\
\hline & 1996 & Fogo acidental atingindo duas parcelas do tratamento \\
\hline \multirow[t]{3}{*}{$\mathrm{T} 2$} & 1983 & $\begin{array}{l}\text { Colheita de árvores comerciais com DAP } \geq 55 \mathrm{~cm} \text {, este tratamento procurou reduzir a área basal em } \\
20 \% \text { do original. }\end{array}$ \\
\hline & 1994 & Anelamento com desvitalização de todas as árvores de espécies não comerciais com DAP $\geq 45 \mathrm{~cm}$. \\
\hline & 1996 & Fogo acidental atingindo cinco parcelas do tratamento \\
\hline \multirow[t]{2}{*}{ T3 } & 1983 & $\begin{array}{l}\text { Colheita de árvores comerciais com DAP } \geq 55 \mathrm{~cm} \text { potenciais com DAP } \geq 65 \mathrm{~cm} \text {, redução da área basal } \\
\text { em } 40 \% \text { do original. }\end{array}$ \\
\hline & 1994 & $\begin{array}{l}\text { Anelamento com desvitalização de todas as árvores de espécies não comerciais com DAP } \geq 15 \mathrm{~cm} \text { e } \\
\text { espécies potenciais com DAP } \geq 65 \mathrm{~cm} \text {. }\end{array}$ \\
\hline \multirow[t]{3}{*}{ T4 } & 1983 & $\begin{array}{l}\text { Colheita de árvores comerciais com DAP } \geq 55 \mathrm{~cm} \text { visando a redução da área basal em } 60 \% \text { do } \\
\text { original. }\end{array}$ \\
\hline & 1994 & $\begin{array}{l}\text { Anelamento com desvitalização de todas as árvores de espécies não comerciais e potenciais com } \\
\text { DAP } \geq 15 \mathrm{~cm} \text {, com exceção do Tauari e do Pau-rosa, }\end{array}$ \\
\hline & 1996 & Fogo acidental atingindo seis parcelas do tratamento \\
\hline
\end{tabular}

\section{Companhia Florestal Monte Dourado-Jari}

O experimento foi iniciado em 1983, com a realização do censo florestal e instalação dos tratamentos (Tabela 2). Em 1985 foi realizada a exploração florestal na área, em 1994 foram aplicados os tratamentos silviculturais com dois tipos de desbaste, sendo um sistemático, com duas intensidades de redução da área basal original em $30 \%$ e $50 \%$, e o outro seletivo.

Em 400ha de floresta, foram instalados três blocos experimentais de 48 ha ambos com bordaduras e faixas com distancia de um quilometro entre os blocos e as estradas. Nos 100 ha de floresta que não foram explorados, foram instalados quatro blocos de um hectare cada, que são utilizados como testemunha. 0 delineamento experimental foi estruturado em blocos ao acaso, com 13 tratamentos, sendo que, doze tratamentos possuem três repetições, e a testemunha possui quatro repetições. 
Tabela 2: Tratamentos utilizados na Companhia Florestal Monte Dourado-Jari.

\begin{tabular}{|c|c|c|}
\hline $\begin{array}{l}\text { Tratamento } \\
\text { Silvicultural }\end{array}$ & Ano & Descrição dos tratamentos silviculturais \\
\hline T0 & 1985 & Floresta sem nenhuma intervenção \\
\hline $\mathrm{T} 1$ & 1985 & $\begin{array}{l}\text { Exploração de } 15 \% \text { do volume total das árvores de DAP > } 60 \mathrm{~cm} \text {, sem redução da área basal após } \\
\text { a exploração. }\end{array}$ \\
\hline \multirow[t]{2}{*}{ T2 } & 1985 & Exploração de $15 \%$ do volume total das árvores de DAP > $60 \mathrm{~cm}$. \\
\hline & 1994 & Redução de $30 \%$ da área basal original através de tratamentos silviculturais. \\
\hline \multirow[t]{2}{*}{ T3 } & 1985 & Exploração de $15 \%$ do volume total das árvores de DAP > $60 \mathrm{~cm}$. \\
\hline & 1994 & Redução de $50 \%$ da área basal original através de tratamentos silviculturais. \\
\hline \multirow[t]{2}{*}{ T4 } & 1985 & Exploração de $15 \%$ do volume total das árvores de DAP > $60 \mathrm{~cm}$, \\
\hline & 1994 & Redução de $70 \%$ da área basal original através de tratamentos silviculturais. \\
\hline T5 & 1985 & $\begin{array}{l}\text { Exploração de } 25 \% \text { do volume total das árvores de DAP }>60 \mathrm{~cm} \text {, sem redução da área basal após } \\
\text { a exploração. }\end{array}$ \\
\hline \multirow[t]{2}{*}{ T6 } & 1985 & Exploração de $25 \%$ do volume total das árvores de DAP > $60 \mathrm{~cm}$. \\
\hline & 1994 & Redução de $30 \%$ da área basal original através de tratamentos silviculturais. \\
\hline \multirow[t]{2}{*}{ T7 } & 1985 & Exploração de $25 \%$ do volume total das árvores de DAP > $60 \mathrm{~cm}$. \\
\hline & 1994 & Redução de 50\% da área basal original através de tratamentos silviculturais. \\
\hline \multirow[t]{2}{*}{ T8 } & 1985 & Exploração de $25 \%$ do volume total das árvores de DAP > $60 \mathrm{~cm}$. \\
\hline & 1994 & Redução de $70 \%$ da área basal original através de tratamentos silviculturais. \\
\hline T9 & 1985 & $\begin{array}{l}\text { Exploração de } 35 \% \text { do volume total das árvores de DAP }>60 \mathrm{~cm} \text {, sem redução da área basal após } \\
\text { a exploração. }\end{array}$ \\
\hline \multirow[t]{2}{*}{ T10 } & 1985 & Exploração de $35 \%$ do volume total das árvores de DAP > $60 \mathrm{~cm}$. \\
\hline & 1994 & Redução de $30 \%$ da área basal original através de tratamentos silviculturais. \\
\hline \multirow[t]{2}{*}{ T11 } & 1985 & Exploração de $35 \%$ do volume total das árvores de DAP > $60 \mathrm{~cm}$. \\
\hline & 1994 & Redução de $50 \%$ da área basal original através de tratamentos silviculturais. \\
\hline \multirow[t]{2}{*}{ T12 } & 1985 & Exploração de $35 \%$ do volume total das árvores de DAP > $60 \mathrm{~cm}$. \\
\hline & 1994 & Redução de $70 \%$ da área basal original através de tratamentos silviculturais. \\
\hline
\end{tabular}

\section{Floresta do Moju}

O experimento foi iniciado em 1995 em 200 ha de floresta monitorada através do censo florestal. Em 1997, foi realizada a exploração florestal de impacto reduzido. Foram extraídas em média 3,3 árvores.ha ${ }^{-1}$, correspondendo a um volume de $23 \mathrm{~m}^{3}$.ha-1, que representou $69 \%$ do volume planejado, 33,5 $\mathrm{m}^{3}$.ha-1 ${ }^{-1}$, com um total de 31 espécies exploradas com diâmetro mínimo de corte (DMC) de $65 \mathrm{~cm}$. Foram realizados inventários florestais nos anos de 1998, 2010 e 2015. Nesta área não houve tratamentos silviculturais após exploração.

\section{PETECO na Fazenda Rio capim}

Foram estabelecidas de forma aleatória, 36 parcelas permanentes de 0,25 ha em 108 ha, divididos em três tratamentos (Tabela 3), composto por 12 parcelas cada, totalizando uma área amostral de 9 ha. (FRANCEZ, 2013). A exploração foi realizada uniformemente, com exceção da área testemunha, conforme as diretrizes estabelecidas no plano de manejo da empresa. Foram extraídas em média 4,0 árvores.ha ${ }^{-1}$ de 16 espécies comerciais, o equivalente a $17,8 \mathrm{~m}^{3} / \mathrm{ha}^{-1}$. Foram realizadas seis medições, em 2003, antes da exploração florestal, que foi realizada no mesmo ano, e em 2004, 2005, 2007, 2008 e 2011.

Tabela 3: Tratamentos utilizados no PETECO na fazenda Rio capim.

\begin{tabular}{|l|l|}
\hline $\begin{array}{l}\text { Tratamentos } \\
\text { Silvicultural }\end{array}$ & Descrição dos tratamentos silviculturais \\
\hline T0 & Controle, representado pela floresta sem nenhuma intervenção. \\
\hline T1 & Exploração de impacto reduzido com retirada apenas dos fustes das árvores comerciais. \\
\hline T2 & $\begin{array}{l}\text { Exploração de impacto reduzido com retirada dos fustes das árvores comerciais, mais a retirada dos } \\
\text { resíduos lenhosos. }\end{array}$ \\
\hline
\end{tabular}




\section{Coleta dos dados}

Foram realizados inventários florestais de espécies arbóreas a partir de $20 \mathrm{~cm}$ diâmetro. Esses inventários foram realizados em diferentes anos antes e após a exploração florestal em cada área experimental conforme a tabela 4.

Tabela 4: Áreas monitoradas e seus respectivos anos de inventário florestal.

\begin{tabular}{|c|c|c|c|c|c|c|c|}
\hline $\begin{array}{l}\text { Tempo antes e depois } \\
\text { da } \\
\text { Colheita } \\
\text { Tratamentos }\end{array}$ & $\begin{array}{l}\text { Flona do } \\
\text { Tapajós } \\
\text { Ano }\end{array}$ & $\begin{array}{l}\text { Tempo antes e } \\
\text { depois da } \\
\text { Colheita e } \\
\text { Tratamentos }\end{array}$ & Jari & $\begin{array}{l}\text { Tempo } \\
\text { antes e } \\
\text { depois da } \\
\text { Colheita }\end{array}$ & Moju & $\begin{array}{ll}\text { Tempo antes } & \text { e } \\
\text { depois da } & \\
\text { Colheita e } & \text { e } \\
\text { Tratamentos } & \end{array}$ & Peteco \\
\hline $1 \mathrm{AE}$ & 1981 & $1 \mathrm{AE}$ & 1984 & $2 \mathrm{AE}$ & 1995 & $\mathrm{AE}$ & 2003 \\
\hline $1 \mathrm{DE}$ & 1983 & $1 \mathrm{DE}$ & 1986 & $1 \mathrm{DE}$ & 1998 & $1 \mathrm{DE}$ & 2004 \\
\hline $5 \mathrm{DE}$ & 1987 & $3 \mathrm{DE}$ & 1988 & $13 \mathrm{DE}$ & 2010 & $2 \mathrm{DE}$ & 2005 \\
\hline $7 \mathrm{DE}$ & 1989 & $5 \mathrm{DE}$ & 1990 & $18 \mathrm{DE}$ & 2015 & $4 \mathrm{DE}$ & 2007 \\
\hline $13 \mathrm{DE} / 1 \mathrm{DT}$ & 1995 & $9 \mathrm{DE}$ & 1994 & & & $5 \mathrm{DE}$ & 2008 \\
\hline 26DE/14DT/11DF & 2008 & 11DE/2DT & 1996 & & & $8 \mathrm{DE}$ & 2011 \\
\hline \multirow[t]{2}{*}{ 30DE/18DT/15DF } & 2012 & 19DE10AT & 2004 & & & & \\
\hline & & 26DE/17AT & 2011 & & & & \\
\hline
\end{tabular}

AE: Antes da exploração; DE Depois da exploração; AT; Antes dos tratamentos Silviculturais, DT: Depois dos tratamentos Silviculturais, DF: Depois do fogo acidental.

\section{Classificação dos grupos}

Foram criados cinco grupos de espécies comerciais para serem analisadas na classe de diâmetro de 20- 49,9 cm e na classe $>50 \mathrm{~cm}$ : a) O primeiro grupo G1 são das espécies comerciais que foram exploradas na área de estudo; b) O segundo grupo $G 2$ são das espécies exploradas atualmente nos municípios onde se encontram as áreas experimentais; c) $O$ terceiro grupo $\mathrm{G} 3$, são das espécies comercializadas atualmente no estado do Pará; d) O quarto grupo G4, são das espécies comercializadas atualmente nos municípios das áreas de estudo monitoradas menos as espécies exploradas na área de estudo; e) $\mathrm{O}$ quinto grupo G5, são das espécies comerciais exploradas no estado do Pará menos as espécies exploradas na área de estudo. Essa lista de espécies comercias se encontram em Pará (2016).

As categorias de grupos de espécies arbóreas comerciais foram G1, G2, G3, G4 e G5, e essa classificação foi realizada através das espécies arbóreas comerciais encontradas nas áreas estudos comparadas com as espécies arbóreas comerciais encontradas em Pará (2016).

\section{Análise dos dados}

Neste trabalho foi estudado duas classes de diâmetro, uma com diâmetro a altura do peito (DAP) entre 20 e 49,9cm, para caracterizar o estoque de madeira reservado para a futura exploração, e outra classe com árvores de DAP $\geq 50 \mathrm{~cm}$, para caracterizar volume disponível para colheita conforme a legislação florestal do Brasil. Para a obtenção de altura das árvores foi utilizada uma equação alométrica, desenvolvida por Dr. Lucas José Mazzei de Freitas da Embrapa Amazônia Oriental que foi produzida a partir de medições de 3964 árvores do sítio Ecosilva, situado em Paragominas.

$$
h=9.6545+0.159256 * D A P
$$

Para a obtenção da área basal foi utilizada equação: 


$$
A B=\pi(D A P) 2 / 40000 \text { para hectare. } \quad \text { Eq2 }
$$

\section{Cálculo do volume comercial}

Para o cálculo do volume comercial foram utilizadas as equações da tabela 5.

Tabela 5: Formulas utilizadas para cada área experimental.

\begin{tabular}{|l|l|l|l|}
\hline Área & Equações Juvenis & DAP & Autor \\
\hline Km114 & $\mathrm{V}=-0,0994+9,1941 * 10^{-4 *} \mathrm{~d}^{2}$ & 20 a $45 \mathrm{~cm}$ & Silva et al. (1984a) \\
\hline Km114 & LnV=-7,62812+2,18090*Ind & $\geq 45$ & Silva et al. (1984b) \\
\hline Jari & $\mathrm{V}=\mathrm{A}^{*} \mathrm{H}^{*} 0,7$ & $20 \mathrm{a} 50 \mathrm{~cm}$ & Pará (2010) \\
\hline Jari & $\mathrm{V}=-0,367921+0,0013446 * \mathrm{~d}^{2}$ & $\geq 50 \mathrm{~cm}$ & Hiramatsu (2008) \\
\hline Moju & $\mathrm{LnV}=-7,49337+2,086952 * \mathrm{Ind}$ & $\geq 20$ & Baima et al. (2001) \\
\hline Peteco & $\mathrm{V}=\mathrm{A}^{*} \mathrm{H}^{*} 0,7$ & $20 \mathrm{a} 48,9 \mathrm{~cm}$ & Pará (2010) \\
\hline Peteco & $\mathrm{V}=0,00003981 \times(\mathrm{d})^{1.91} \times(\mathrm{h})^{1.17}$ & $>49$ & Formula utilizada na CIKEL \\
\hline
\end{tabular}

Nas áreas de estudo foram cálculos os volumes de espécies comercias que se encontram nessas áreas e comparados com a lista de espécies comerciais do estado e municípios. Foram divididas em classe diamétrica $20-49,9 \mathrm{~cm}$ e $>50 \mathrm{~cm}$. Foram calculados o volume por classe diamétrica e grupo. Em todas as áreas de estudo as explorações florestais foram de impacto reduzido.

\section{RESULTADOS}

\section{Volume de madeira por grupo}

\section{Flona do Tapajós}

\section{Primeiro grupo}

Conforme a Tabela 6 referente ao grupo G1 de árvores, os tratamentos T2, T3 e T4, recuperaram o volume de madeira 30 anos após a exploração na classe de diâmetro de $20-49,9 \mathrm{~cm}$. Quanto a classe de diâmetro $\geq 50 \mathrm{~cm}$ somente o T0, recuperou o estoque volumétrico de madeira, após 30 anos da exploração florestal de impacto reduzido.

Tabela 6: Volume de madeira $\left(\mathrm{m}^{3} / \mathrm{ha}\right)$ do grupo $\mathrm{G} 1$ nos tratamentos silviculturais por classe diamétrica na Floresta Nacional do Tapajós, Pará.

\begin{tabular}{|l|l|l|l|l|l|}
\hline \multirow{2}{*}{ Tempo } & T0 & T1 & T2 & T3 & T4 \\
\cline { 2 - 6 } & $20-49,9$ & $20-49,9$ & $20-49,9$ & $20-49,9$ & $20-49,9$ \\
\hline $1 \mathrm{AE}$ & 0 & 16,95 & 16,75 & 22,5 & 11,09 \\
\hline 1DE & 14,76 & 11,29 & 13,77 & 20,07 & 9,36 \\
\hline 7DE & 17,49 & 14,5 & 12,46 & 18,65 & 9,66 \\
\hline $13 \mathrm{DE} / 1 \mathrm{DT}$ & 13,65 & 16,27 & 11,36 & 18,93 & 10,93 \\
\hline 26DE/14DT/11DF & 14,7 & 19,61 & 12,09 & 18,13 & 13,44 \\
\hline $30 \mathrm{DE} / 18 \mathrm{DT} / 15 \mathrm{DF}$ & 16,96 & 24,34 & 16,12 & 28,02 & 23,64 \\
\hline Tempo & 12,56 & 16,48 & 17,7 & 31,43 & 25,41 \\
\hline & & & & & \\
\hline $1 \mathrm{AE}$ & $\geq 50$ & $\geq 50$ & $\geq 50$ & $\geq 50$ & $\geq 50$ \\
\hline $1 \mathrm{DE}$ & 0 & 54,1 & 45,86 & 53,72 & 40,45 \\
\hline 5DE & 38,13 & 11,46 & 5,53 & 7,16 & 4,67 \\
\hline 7DE & 45,61 & 8,03 & 11,93 & 10,37 & 9,51 \\
\hline $13 \mathrm{DE} / 1 \mathrm{DT}$ & 40,38 & 8,77 & 14,85 & 11,78 & 4,47 \\
\hline $26 \mathrm{DE} / 14 \mathrm{DT} / 11 \mathrm{DF}$ & 40,28 & 12,71 & 11,36 & 17,52 & 13,63 \\
\hline $30 \mathrm{DE} / 18 \mathrm{DT} / 15 \mathrm{DF}$ & 41,7 & 15,96 & 17,63 & 25,88 & 16,87 \\
\hline
\end{tabular}


A Tabela 7 mostra o grupo G2 de árvores, em que somente o tratamento T0 na classe de DAP $\geq 50$ cm aumentou o seu volume de madeira após a exploração florestal, recuperando seu estoque volumétrico.

Tabela 7: Volume de madeira $\left(\mathrm{m}^{3} / \mathrm{ha}\right)$ do grupo $\mathrm{G} 2$ nos tratamentos silviculturais por classe diamétrica na Floresta Nacional do Tapajós, Pará.

\begin{tabular}{|c|c|c|c|c|c|}
\hline Tempo & T0 & T1 & $\mathrm{T} 2$ & T3 & $\mathrm{T4}$ \\
\hline & $20-49,9$ & $20-49,9$ & $20-49,9$ & $20-49,9$ & $20-49,9$ \\
\hline $1 \mathrm{AE}$ & 0 & 7,92 & 8,58 & 9,22 & 6,28 \\
\hline $1 \mathrm{DE}$ & 10,36 & 5,2 & 9,62 & 8,24 & 7,38 \\
\hline $5 \mathrm{DE}$ & 13,63 & 7,31 & 8,35 & 6,23 & 4,16 \\
\hline $7 D E$ & 11,43 & 6,67 & 8,97 & 6,37 & 5,27 \\
\hline 13DE/1DT & 12,45 & 7,63 & 9,75 & 6,11 & 6,28 \\
\hline 26DE/14DT/11DF & 12,82 & 8,03 & 10,66 & 9,12 & 6,88 \\
\hline 30DE/18DT/15DF & 8,55 & 5,23 & 9,34 & 8,25 & 5,8 \\
\hline \multicolumn{6}{|l|}{ Tempo } \\
\hline & $\geq 50$ & $\geq 50$ & $\geq 50$ & $\geq 50$ & $\geq 50$ \\
\hline $1 \mathrm{AE}$ & 0 & 36,45 & 28,22 & 54,66 & 25,37 \\
\hline $1 \mathrm{DE}$ & 21,71 & 12,99 & 11,03 & 16,52 & 3,84 \\
\hline $5 \mathrm{DE}$ & 24,84 & 15,77 & 17,25 & 18,75 & 3,89 \\
\hline $7 \mathrm{DE}$ & 23,61 & 15,47 & 11,56 & 19,22 & 5,09 \\
\hline 13DE/1DT & 29,69 & 16,16 & 11,82 & 19,8 & 3,18 \\
\hline 26DE/14DT/11DF & 30,42 & 19,08 & 15,22 & 19,72 & 6,34 \\
\hline 30DE/18DT/15DF & 28,78 & 21,73 & 13,99 & 21,39 & 8,67 \\
\hline
\end{tabular}

Quanto ao terceiro grupo de árvores G3 (Tabela 8), para os indivíduos da primeira classe diamétrica de ambas as classes, todos os tratamentos recuperaram o seu volume inicial. Já para a segunda classe diamétrica somente o tratamento que não teve exploração teve um aumento no volume em relação ao ano antes da exploração.

Tabela 8: Volume de madeira $\left(\mathrm{m}^{3} / \mathrm{ha}\right)$ do grupo G3 nos tratamentos silviculturais por classe diamétrica na Floresta Nacional do Tapajós, Pará.

\begin{tabular}{|c|c|c|c|c|c|}
\hline Tempo & TO & T1 & $\mathrm{T} 2$ & T3 & T4 \\
\hline & $20-49,9$ & $20-49,9$ & $20-49,9$ & $20-49,9$ & $20-49,9$ \\
\hline $1 \mathrm{AE}$ & 0 & 45,34 & 54,7 & 55,79 & 44,28 \\
\hline $1 \mathrm{DE}$ & 50,69 & 38,52 & 54,42 & 48,26 & 39,63 \\
\hline $5 \mathrm{DE}$ & 54,14 & 44,74 & 54,66 & 46,25 & 35,99 \\
\hline $7 D E$ & 52,92 & 53,64 & 58,39 & 51,38 & 44,16 \\
\hline 13DE/1DT & 54,86 & 70,81 & 57,11 & 39,7 & 44,15 \\
\hline 26DE/14DT/11DF & 56,63 & 79,19 & 69,93 & 54,07 & 66,85 \\
\hline 30DE/18DT/15DF & 52,5 & 57,69 & 68,47 & 58,97 & 56,5 \\
\hline \multicolumn{6}{|l|}{ Tempo } \\
\hline & $\geq 50$ & $\geq 50$ & $\geq 50$ & $\geq 50$ & $\geq 50$ \\
\hline $1 \mathrm{AE}$ & 0 & 111,78 & 73,63 & 98 & 63,53 \\
\hline $1 \mathrm{DE}$ & 67,11 & 63,25 & 54,68 & 52,69 & 30,49 \\
\hline $5 \mathrm{DE}$ & 82,98 & 65,6 & 61,58 & 57,85 & 37,88 \\
\hline $7 D E$ & 78,73 & 68,5 & 68,12 & 60,54 & 47,08 \\
\hline 13DE/1DT & 71,97 & 78,5 & 61,46 & 65,95 & 55,85 \\
\hline 26DE/14DT/11DF & 74,53 & 79,39 & 72,27 & 79,92 & 59,26 \\
\hline 30DE/18DT/15DF & 77,09 & 82,56 & 65,94 & 84,34 & 48,08 \\
\hline
\end{tabular}

Para o quarto grupo de árvores G4 (Tabela 9), somente o tratamento T4 não recuperou seu volume na classes diamétrica de $20-49,9 \mathrm{~cm}$. Os tratamentos T0, T1 e T4 teve um aumento no volume de madeira após 30 anos da exploração florestal na classe $\geq 50 \mathrm{~cm}$.

Quanto ao quinto grupo de árvores G5 (Tabela 10), de classe de diâmetro 20 - 49,9 cm, os tratamentos T0, T1 e T2 recuperaram o seu estoque volumétrico, já na segunda classe diamétrica $\geq 50 \mathrm{~cm}$ 
todos os tratamentos recuperaram o seu volume de madeira após a exploração florestal.

Tabela 9: Volume de madeira $\left(\mathrm{m}^{3} / \mathrm{ha}\right)$ do grupo $\mathrm{G} 4$ nos tratamentos silviculturais por classe diamétrica na Floresta Nacional do Tapajós, Pará.

\begin{tabular}{|c|c|c|c|c|c|}
\hline Tempo & T0 & $\mathrm{T} 1$ & $\mathrm{~T} 2$ & T3 & T4 \\
\hline & $20-49,9$ & $20-49,9$ & $20-49,9$ & $20-49,9$ & $20-49,9$ \\
\hline $1 \mathrm{AE}$ & 0 & 2,65 & 2,77 & 3,2 & 4,01 \\
\hline $1 \mathrm{DE}$ & 3,31 & 1,81 & 4,98 & 2,1 & 5,93 \\
\hline $5 \mathrm{DE}$ & 5,5 & 2,77 & 4,06 & 2,6 & 3,1 \\
\hline 7DE & 4,35 & 2,3 & 5,12 & 2,69 & 3,82 \\
\hline 13DE/1DT & 5,34 & 2,15 & 5,43 & 3,72 & 4,41 \\
\hline 26DE/14DT/11DF & 6,35 & 3,72 & 6,75 & 6,51 & 5,03 \\
\hline 30DE/18DT/15DF & 4,11 & 2,65 & 5,93 & 5,44 & 2,41 \\
\hline \multicolumn{6}{|l|}{ Tempo } \\
\hline & $\geq 50$ & $\geq 50$ & $\geq 50$ & $\geq 50$ & $\geq 50$ \\
\hline $1 \mathrm{AE}$ & 0 & 11,59 & 11,13 & 15,26 & 1,78 \\
\hline $1 \mathrm{DE}$ & 3,32 & 11,7 & 10,06 & 15,67 & 2,93 \\
\hline $5 D E$ & 4,92 & 14,38 & 12,3 & 15,22 & 2,84 \\
\hline $7 \mathrm{DE}$ & 4,36 & 13,16 & 8,52 & 15,57 & 4 \\
\hline 13DE/1DT & 7,76 & 13,67 & 6,27 & 14,02 & 1,92 \\
\hline 26DE/14DT/11DF & 4,57 & 13,72 & 7,7 & 12,01 & 1,03 \\
\hline 30DE/18DT/15DF & 3,37 & 13,97 & 5,99 & 13,04 & 5,5 \\
\hline
\end{tabular}

Tabela 10: Volume de madeira $\left(\mathrm{m}^{3} / \mathrm{ha}\right)$ do grupo $\mathrm{G} 5$ nos tratamentos silviculturais por classe diamétrica na Floresta Nacional do Tapajós, Pará.

\begin{tabular}{|l|l|l|l|l|l|}
\hline & T0 & T1 & T2 & T3 & T4 \\
\hline Tempo & $20-49,9$ & $20-49,9$ & $20-49,9$ & $20-49,9$ & $20-49,9$ \\
\hline $1 \mathrm{AE}$ & 0 & 29,06 & 38,13 & 33,29 & 33,34 \\
\hline $1 \mathrm{DE}$ & 35,93 & 27,22 & 40,65 & 28,19 & 30,28 \\
\hline SDE & 37,22 & 30,24 & 42,98 & 27,83 & 27,25 \\
\hline $7 \mathrm{DE}$ & 39,39 & 37,49 & 47,19 & 32,79 & 33,4 \\
\hline $13 \mathrm{DE} / 1 \mathrm{DT}$ & 40,5 & 51,2 & 45,33 & 22 & 32,03 \\
\hline $26 \mathrm{DE} / 14 \mathrm{DT} / 11 \mathrm{DF}$ & 41,18 & 55,69 & 54,53 & 26,83 & 44,9 \\
\hline $30 \mathrm{DE} / 18 \mathrm{DT} / 15 \mathrm{DF}$ & 40,28 & 42,78 & 50,91 & 28,7 & 32,42 \\
\hline Tempo & & & & & \\
\hline & $\geq 50$ & $\geq 50$ & $\geq 50$ & 250 & $\geq 50$ \\
\hline $1 \mathrm{AE}$ & 0 & 60,25 & 42,16 & 45,26 & 28,69 \\
\hline $1 \mathrm{DE}$ & 31,02 & 51,8 & 49,16 & 46,67 & 25,82 \\
\hline 5DE & 39,58 & 57,57 & 49,65 & 48,92 & 29,32 \\
\hline 7DE & 41,52 & 59,73 & 53,27 & 50,34 & 42,61 \\
\hline $13 \mathrm{DE} / 1 \mathrm{DT}$ & 36,34 & 65,79 & 50,1 & 50,34 & 42,22 \\
\hline $26 \mathrm{DE} / 14 \mathrm{DT} / 11 \mathrm{DF}$ & 35,93 & 63,43 & 54,65 & 57,04 & 43,78 \\
\hline $30 \mathrm{DE} / 18 \mathrm{DT} / 15 \mathrm{DF}$ & 36,05 & 62,94 & 52,46 & 59,1 & 36,57 \\
\hline
\end{tabular}

\section{Companhia Monte Dourado-Jari}

Para o primeiro grupo de árvores(Tabela 11), os tratamentos silviculturais T0, T1 e T11 tiveram resiliência, pois aumentou seu volume 26 anos após a exploração florestal na classe de diamétrica de 20 49,9 cm, já na segunda classe diamétrica somente o T0 recuperou seu volume.

Tabela 11: Volume de madeira $\left(\mathrm{m}^{3} / \mathrm{ha}\right)$ do grupo G1 nos tratamentos silviculturais por classe diamétrica na Companhia Monte Dourado-Jari, Amapá.

\begin{tabular}{|l|l|l|l|l|l|l|l|l|l|l|l|l|l|}
\hline & T0 & T1 & T2 & T3 & T4 & T5 & T6 & T7 & T8 & T9 & T10 & T11 & T12 \\
\hline Tempo & & & & & & & & & & & & & \\
\hline & $20-$ & $20-$ & $20-$ & $20-$ & $20-$ & $20-$ & $20-$ & $20-$ & $20-$ & $20-$ & $20-$ & $20-$ & $20-$ \\
& 49,9 & 49,9 & 49,9 & 49,9 & 49,9 & 49,9 & 49,9 & 49,9 & 49,9 & 49,9 & 49,9 & 49,9 & 49,9 \\
\hline 1AE & 15,34 & 19,05 & 23,83 & 23,83 & 22,42 & 23,07 & 18,55 & 15,73 & 20,25 & 19,66 & 22,71 & 20,07 & 19,89 \\
\hline $1 D E$ & 16,08 & 17,57 & 20,82 & 22,72 & 21 & 18,74 & 17,67 & 14,88 & 19,04 & 19,14 & 20,46 & 19,87 & 17,6 \\
\hline $3 D E$ & 16,72 & 17,69 & 19,47 & 23,87 & 21,26 & 18,03 & 16,86 & 15,61 & 17,97 & 17,47 & 19,63 & 18,86 & 15,84 \\
\hline 5DE & 17,2 & 17,82 & 18,73 & 23,68 & 21 & 17 & 16,89 & 13,25 & 19,15 & 16,59 & 20,5 & 18,49 & 15,68 \\
\hline
\end{tabular}




\begin{tabular}{|c|c|c|c|c|c|c|c|c|c|c|c|c|c|}
\hline 9DE & 17,47 & 17,88 & 19,52 & 25,16 & 21,49 & 16,79 & 16,7 & 13,86 & 16,95 & 17,09 & 20,06 & 19,88 & 15,43 \\
\hline $\begin{array}{l}\text { 11DE/2D } \\
T\end{array}$ & 17,6 & 18,75 & 19,06 & 24,79 & 21,01 & 16,44 & 17,73 & 14,68 & 17,06 & 17,26 & 21,27 & 19,18 & 15,64 \\
\hline $\begin{array}{l}\text { 19AE/10 } \\
\text { AT }\end{array}$ & 18,05 & 21,33 & 20,53 & 24,13 & 20,76 & 16,55 & 17,53 & 15,24 & 18,53 & 20,43 & 20,33 & 20,86 & 17,97 \\
\hline $\begin{array}{l}26 \mathrm{DE} / 17 \\
\text { AT }\end{array}$ & 16,52 & 20,66 & 20,13 & 20,92 & 17,93 & 16,92 & 16,3 & 15,41 & 18,4 & 18,78 & 20,71 & 23,03 & 18,3 \\
\hline \multicolumn{14}{|l|}{ Tempo } \\
\hline & $\geq 50$ & $\geq 50$ & $\geq 50$ & $\geq 50$ & $\geq 50$ & $\geq 50$ & $\geq 50$ & $\geq 50$ & $\geq 50$ & $\geq 50$ & $\geq 50$ & $\geq 50$ & $\geq 50$ \\
\hline $1 \mathrm{AE}$ & 57,2 & 96,4 & 80,11 & $\begin{array}{l}125,9 \\
2\end{array}$ & $\begin{array}{l}123,9 \\
7\end{array}$ & $\begin{array}{l}118,1 \\
4\end{array}$ & $\begin{array}{l}113,1 \\
3\end{array}$ & 90,84 & $\begin{array}{l}124,1 \\
2\end{array}$ & $\begin{array}{l}104,0 \\
6\end{array}$ & 132,9 & 89 & $\begin{array}{l}103,8 \\
2\end{array}$ \\
\hline $1 \mathrm{DE}$ & 57,74 & 69,62 & 51,72 & $\begin{array}{l}104,6 \\
5\end{array}$ & 103,7 & 72,89 & 78,22 & 48,46 & 60,04 & 44,1 & 54,33 & 40,49 & 42,24 \\
\hline $3 D E$ & 58,61 & 72,65 & 54,72 & 106,3 & $\begin{array}{l}101,4 \\
2\end{array}$ & 75,27 & 76,62 & 49,44 & 60,98 & 45,69 & 57,59 & 42,37 & 46,37 \\
\hline $5 \mathrm{DE}$ & 56,76 & 69,73 & 57,8 & $\begin{array}{l}105,8 \\
1\end{array}$ & $\begin{array}{l}101,1 \\
9\end{array}$ & 74,83 & 74,86 & 52,29 & 59,94 & 48,88 & 58,89 & 34,29 & 45,15 \\
\hline 9DE & 59,35 & 72,04 & 55,27 & $\begin{array}{l}110,6 \\
4\end{array}$ & 95,87 & 76,84 & 76,93 & 54,18 & 65,95 & 53,29 & 62,53 & 36,54 & 47,68 \\
\hline $\begin{array}{l}\text { 11DE/2D } \\
T\end{array}$ & 60,62 & 73,1 & 56,31 & $\begin{array}{l}110,4 \\
1\end{array}$ & 89,29 & 79,6 & 77,61 & 55,15 & 65,6 & 54,08 & 63,7 & 39,25 & 48,79 \\
\hline $\begin{array}{l}\text { 19AE/10 } \\
\text { AT }\end{array}$ & 56,41 & 77,38 & 55,39 & $\begin{array}{l}100,7 \\
1\end{array}$ & 76,36 & 82,83 & 80,65 & 52,38 & 60,73 & 56,2 & 57,38 & 40,98 & 53,76 \\
\hline $\begin{array}{l}26 \mathrm{DE} / 17 \\
\text { AT }\end{array}$ & 57,53 & 78,73 & 56,03 & $\begin{array}{l}100,6 \\
9 \\
\end{array}$ & 81,23 & 82,15 & 75,15 & 43,95 & 67,63 & 60,58 & 63,79 & 38,31 & 43,7 \\
\hline
\end{tabular}

Quanto ao segundo grupo (Tabela 12), a classe diamétrica $20-49,9 \mathrm{~cm}$ teve resiliência para os tratamentos silviculturais T0, T1, T2, T6, T10 e T11 e para classe diamétrica $\geq 50 \mathrm{~cm}$ nenhum dos tratamentos silviculturais recuperou o volume, após a exploração florestal.

Tabela 12: Volume de madeira $\left(\mathrm{m}^{3} / \mathrm{ha}\right.$ ) do grupo $\mathrm{G} 2$ nos tratamentos silviculturais por classe diamétrica na Companhia Monte Dourado-Jari, Amapá.

\begin{tabular}{|l|l|l|l|l|l|l|l|l|l|l|l|l|l|}
\hline & $\mathrm{T} 0$ & $\mathrm{~T} 1$ & $\mathrm{~T} 2$ & $\mathrm{~T} 3$ & $\mathrm{~T} 4$ & $\mathrm{~T} 5$ & $\mathrm{~T} 6$ & $\mathrm{~T} 7$ & $\mathrm{~T} 8$ & $\mathrm{~T} 9$ & $\mathrm{~T} 10$ & $\mathrm{~T} 11$ & $\mathrm{~T} 12$ \\
\hline Tempo & & & & & & & & & & & & & \\
\hline & $20-$ & $20-$ & $20-$ & $20-$ & $20-$ & $20-$ & $20-$ & $20-$ & $20-$ & $20-$ & $20-$ & $20-$ & $20-$ \\
& 49,9 & 49,9 & 49,9 & 49,9 & 49,9 & 49,9 & 49,9 & 49,9 & 49,9 & 49,9 & 49,9 & 49,9 & 49,9 \\
\hline 1AE & 10,93 & 9,41 & 13,43 & 12,59 & 11,46 & 19,44 & 10,29 & 13,5 & 15,52 & 12,91 & 14,82 & 12,12 & 13,36 \\
\hline 1DE & 11,57 & 9 & 13,45 & 13,19 & 10,05 & 15,36 & 10,37 & 13,09 & 15,02 & 12,99 & 12,59 & 12,35 & 10,86 \\
\hline 3DE & 12,12 & 8,7 & 12,36 & 13,78 & 9,8 & 14,81 & 10,14 & 13,39 & 13,8 & 10,03 & 12,7 & 11,39 & 7,69 \\
\hline 5DE & 12,57 & 9,05 & 11,89 & 14,14 & 10,74 & 15,12 & 10,74 & 11,18 & 14,62 & 9,89 & 13,53 & 11,79 & 8,26 \\
\hline 9DE & 12,34 & 8,71 & 13,23 & 15,01 & 11,34 & 14,57 & 11,89 & 9,51 & 12,38 & 9,53 & 13,14 & 12,53 & 7,91 \\
\hline 11DE/2DT & 13,04 & 9,1 & 13,31 & 15 & 12,1 & 13,91 & 12,6 & 10,69 & 12,71 & 9,98 & 14,04 & 12,66 & 8,49 \\
\hline 19AE/10AT & 13,83 & 10,1 & 14,08 & 13,27 & 13,29 & 14,47 & 11,25 & 11,12 & 13,34 & 11,36 & 14,59 & 12,58 & 9,55 \\
\hline 26DE/17AT & 13,21 & 9,53 & 13,93 & 11,62 & 10,62 & 13,5 & 11,17 & 10,58 & 14,18 & 10,65 & 16,3 & 15,66 & 10,39 \\
\hline Tempo & & & & & & & & & & & & & \\
\hline & $\geq 50$ & $\geq 50$ & $\geq 50$ & $\geq 50$ & $\geq 50$ & $\geq 50$ & $\geq 50$ & $\geq 50$ & $\geq 50$ & $\geq 50$ & $\geq 50$ & $\geq 50$ & $\geq 50$ \\
\hline 1AE & 71,81 & 81,47 & 60,22 & 116,32 & 108,09 & 96,2 & 86,6 & 75,35 & 106,72 & 82,13 & 119,9 & 77,45 & 89,8 \\
\hline 1DE & 72,35 & 54,55 & 37,83 & 92,87 & 87,63 & 51,14 & 57 & 39,37 & 44,41 & 34,3 & 54,74 & 32,95 & 36,74 \\
\hline 3DE & 73,41 & 57,25 & 39,48 & 94,36 & 89,41 & 53,37 & 56,46 & 40,58 & 46,17 & 37,85 & 57,25 & 34,58 & 41,7 \\
\hline 5DE & 71,61 & 58,25 & 40,9 & 95,15 & 90,36 & 51,42 & 56,8 & 36,45 & 44,64 & 36,92 & 58,7 & 29,22 & 39,46 \\
\hline 9DE & 74,57 & 61,2 & 37,69 & 98,62 & 88,73 & 52,53 & 58,1 & 40,07 & 49,03 & 41 & 61,3 & 31,41 & 41,7 \\
\hline 11DE/2DT & 75,58 & 62,03 & 38,25 & 93,2 & 85,89 & 54,96 & 58,5 & 39,88 & 50,16 & 40,71 & 62,7 & 28,7 & 42,58 \\
\hline 19AE/10AT & 67,13 & 65,48 & 39,24 & 96,67 & 69,68 & 60,54 & 55,79 & 40,26 & 46,95 & 43,75 & 49,92 & 36,03 & 47,87 \\
\hline 26DE/17AT & 58,35 & 64,05 & 36,2 & 93,28 & 74,94 & 62,97 & 49,27 & 33,91 & 52,75 & 47,22 & 54,94 & 29,47 & 36,55 \\
\hline
\end{tabular}

Quanto ao terceiro grupo de árvores (Tabela 13), para a primeira classe diamétrica somente o tratamento T5 não recuperou o seu volume de madeira inicial, já para as árvores da segunda classe diamétrica nenhum dos tratamentos obtiveram resiliência. 
Tabela 13: Volume de madeira $\left(\mathrm{m}^{3} / \mathrm{ha}\right.$ ) do grupo $\mathrm{G} 3$ nos tratamentos silviculturais por classe diamétrica na Companhia Monte Dourado-Jari, Amapá.

\begin{tabular}{|c|c|c|c|c|c|c|c|c|c|c|c|c|c|}
\hline & T0 & $\mathrm{T} 1$ & $\mathrm{~T} 2$ & T3 & T4 & T5 & T6 & $\mathrm{T7}$ & T8 & T9 & T10 & T11 & T12 \\
\hline \multicolumn{14}{|l|}{ Tempo } \\
\hline & $\begin{array}{l}20- \\
49,9\end{array}$ & $\begin{array}{l}20- \\
49,9\end{array}$ & $\begin{array}{l}20- \\
49,9\end{array}$ & $\begin{array}{l}20- \\
49,9\end{array}$ & $\begin{array}{l}20- \\
49,9\end{array}$ & $\begin{array}{l}20- \\
49,9\end{array}$ & $\begin{array}{l}20- \\
49,9\end{array}$ & $\begin{array}{l}20- \\
49,9\end{array}$ & $\begin{array}{l}20- \\
49,9\end{array}$ & $\begin{array}{l}20- \\
49,9\end{array}$ & $\begin{array}{l}20- \\
49,9\end{array}$ & $\begin{array}{l}20- \\
49,9\end{array}$ & $\begin{array}{l}20- \\
49,9\end{array}$ \\
\hline $1 \mathrm{AE}$ & 43,15 & 44,33 & 48,78 & 38,01 & 46,74 & 49,8 & 36,48 & 40,53 & 45,12 & 40,03 & 41,71 & 49,13 & $\begin{array}{l}41,5 \\
3\end{array}$ \\
\hline $1 \mathrm{DE}$ & 44,64 & 42,17 & 46,36 & 38,34 & 44,74 & 42,45 & 37,49 & 39,77 & 41,9 & 39,46 & 37,72 & 48,47 & $\begin{array}{l}36,9 \\
5\end{array}$ \\
\hline $3 D E$ & 46,36 & 42,51 & 45,04 & 40,17 & 44,63 & 41,26 & 39,12 & 40,89 & 40,51 & 37,13 & 36,62 & 46,04 & $\begin{array}{l}34,1 \\
4\end{array}$ \\
\hline $5 \mathrm{DE}$ & 47,47 & 43,58 & 44,84 & 40,69 & 45,24 & 40,48 & 40,18 & 38,7 & 43,42 & 37,29 & 38,19 & 47,75 & $\begin{array}{l}34,8 \\
9\end{array}$ \\
\hline $9 D E$ & 49,62 & 45,41 & 47,62 & 42,89 & 46,73 & 43,04 & 42,67 & 39,57 & 43,95 & 40,03 & 40,99 & 50 & $\begin{array}{l}37,1 \\
5\end{array}$ \\
\hline 11DE/2DT & 50,81 & 45,99 & 44,89 & 40,12 & 45,99 & 43,2 & 41,66 & 37,46 & 45,42 & 42,54 & 44,99 & 45,18 & $\begin{array}{l}37,1 \\
4\end{array}$ \\
\hline $\begin{array}{l}\text { 19AE/10A } \\
T\end{array}$ & 49,78 & 50,47 & 48,95 & 45,23 & 48,4 & 49,42 & 44,05 & 41,65 & 49,73 & 49,99 & 52,94 & 52,67 & $\begin{array}{l}45,4 \\
4\end{array}$ \\
\hline $\begin{array}{l}\text { 26DE/17A } \\
T\end{array}$ & 51,53 & 51,04 & 52,12 & 41,25 & 48,6 & 47,45 & 47,24 & 43,74 & 54,43 & 49,9 & 59,86 & 63,22 & $\begin{array}{l}46,0 \\
1 \\
\end{array}$ \\
\hline \multicolumn{14}{|l|}{ Tempo } \\
\hline & $\geq 50$ & $\geq 50$ & $\geq 50$ & $\geq 50$ & $\geq 50$ & $\geq 50$ & $\geq 50$ & $\geq 50$ & $\geq 50$ & $\geq 50$ & $\geq 50$ & $\geq 50$ & $\geq 50$ \\
\hline $1 \mathrm{AE}$ & $\begin{array}{l}118,0 \\
6\end{array}$ & $\begin{array}{l}128,4 \\
9 \\
\end{array}$ & $\begin{array}{l}102,8 \\
1\end{array}$ & 147,3 & $\begin{array}{l}148,0 \\
1\end{array}$ & $\begin{array}{l}151,7 \\
5\end{array}$ & $\begin{array}{l}139,0 \\
2\end{array}$ & $\begin{array}{l}133,5 \\
5\end{array}$ & $\begin{array}{l}148,3 \\
5\end{array}$ & $\begin{array}{l}135,3 \\
6\end{array}$ & $\begin{array}{l}156,4 \\
5\end{array}$ & $\begin{array}{l}125,8 \\
7 \\
\end{array}$ & $\begin{array}{l}122, \\
1\end{array}$ \\
\hline $1 \mathrm{DE}$ & $\begin{array}{l}119,3 \\
8\end{array}$ & $\begin{array}{l}100,5 \\
6\end{array}$ & 75,63 & $\begin{array}{l}125,2 \\
5\end{array}$ & $\begin{array}{l}129,0 \\
4\end{array}$ & $\begin{array}{l}106,0 \\
5\end{array}$ & $\begin{array}{l}103,1 \\
1\end{array}$ & 91,28 & 83,54 & 80,44 & 83,59 & 77,61 & $\begin{array}{l}64,0 \\
3\end{array}$ \\
\hline $3 D E$ & $\begin{array}{l}121,4 \\
2\end{array}$ & 97,62 & 73,05 & $\begin{array}{l}126,0 \\
5\end{array}$ & $\begin{array}{l}131,2 \\
6\end{array}$ & $\begin{array}{l}109,2 \\
5\end{array}$ & 98,03 & 93,22 & 85,03 & 84,97 & 88,28 & 82,38 & $\begin{array}{l}69,7 \\
7 \\
\end{array}$ \\
\hline $5 D E$ & $\begin{array}{l}114,5 \\
3\end{array}$ & 94,13 & 77,27 & 122,1 & $\begin{array}{l}132,6 \\
7\end{array}$ & $\begin{array}{l}102,6 \\
6\end{array}$ & 96,86 & 90,64 & 84,52 & 87,5 & 91,31 & 69,51 & 67,5 \\
\hline $9 D E$ & 117,4 & $\begin{array}{l}100,0 \\
6\end{array}$ & 75,49 & $\begin{array}{l}127,7 \\
6\end{array}$ & $\begin{array}{l}132,8 \\
8\end{array}$ & $\begin{array}{l}107,7 \\
8\end{array}$ & 98,59 & 97,18 & 89,81 & 89,33 & 97,83 & 76,8 & $\begin{array}{l}71,5 \\
4\end{array}$ \\
\hline $11 \mathrm{DE} / 2 \mathrm{DT}$ & $\begin{array}{l}116,1 \\
9\end{array}$ & 101,8 & 75,77 & $\begin{array}{l}123,7 \\
7 \\
\end{array}$ & $\begin{array}{l}124,2 \\
4\end{array}$ & $\begin{array}{l}109,9 \\
7\end{array}$ & 98,59 & 91,96 & 88,74 & 85,15 & $\begin{array}{l}100,2 \\
8\end{array}$ & 73,74 & $\begin{array}{l}72,7 \\
7 \\
\end{array}$ \\
\hline $\begin{array}{l}\text { 19AE/10A } \\
T\end{array}$ & $\begin{array}{l}104,8 \\
5\end{array}$ & $\begin{array}{l}108,8 \\
2\end{array}$ & 78,18 & $\begin{array}{l}114,4 \\
5\end{array}$ & $\begin{array}{l}106,2 \\
8\end{array}$ & $\begin{array}{l}110,8 \\
5\end{array}$ & $\begin{array}{l}101,2 \\
6\end{array}$ & 92,56 & 88,1 & 92,25 & 93,79 & 79,11 & $\begin{array}{l}80,3 \\
4\end{array}$ \\
\hline $\begin{array}{l}\text { 26DE/17A } \\
\mathrm{T}\end{array}$ & 94,48 & $\begin{array}{l}111,9 \\
7\end{array}$ & 71,35 & $\begin{array}{l}114,3 \\
9\end{array}$ & $\begin{array}{l}116,4 \\
9\end{array}$ & $\begin{array}{l}119,1 \\
4\end{array}$ & 98,76 & 89,19 & 97,47 & 99,32 & $\begin{array}{l}105,2 \\
9\end{array}$ & 72,82 & $\begin{array}{l}69,3 \\
7 \\
\end{array}$ \\
\hline
\end{tabular}

Para o quarto grupo de árvores (Tabela 14), os tratamentos T0, T1, T2, T3, T4, T6, T8, T10, T11, T12 tiveram resiliência para a primeira classe diamétrica, para a segunda classe os tratamentos $T 1, T 5, T 7, T 8, T 9$ e T12 recuperaram o seu volume inicial.

Tabela 14: Volume de madeira $\left(\mathrm{m}^{3} / \mathrm{ha}\right)$ do grupo $\mathrm{G} 4$ nos tratamentos silviculturais por classe diamétrica na Companha Monte Dourado-Jari, Amapá.

\begin{tabular}{|c|c|c|c|c|c|c|c|c|c|c|c|c|c|}
\hline & T0 & T1 & $\mathrm{T} 2$ & T3 & $\mathrm{T} 4$ & T5 & T6 & $\mathrm{T7}$ & $\mathrm{T} 8$ & T9 & T10 & T11 & T12 \\
\hline \multicolumn{14}{|l|}{ Tempo } \\
\hline & $\begin{array}{l}20- \\
49,9 \\
\end{array}$ & $\begin{array}{l}20- \\
49,9\end{array}$ & $\begin{array}{l}20- \\
49,9 \\
\end{array}$ & $\begin{array}{l}20- \\
49,9\end{array}$ & $\begin{array}{l}20- \\
49,9\end{array}$ & $\begin{array}{l}20- \\
49,9\end{array}$ & $\begin{array}{l}20- \\
49,9 \\
\end{array}$ & $\begin{array}{l}20- \\
49,9\end{array}$ & $\begin{array}{l}20- \\
49,9\end{array}$ & $\begin{array}{l}20- \\
49,9 \\
\end{array}$ & $\begin{array}{l}20- \\
49,9 \\
\end{array}$ & $\begin{array}{l}20- \\
49,9\end{array}$ & $\begin{array}{l}20- \\
49,9 \\
\end{array}$ \\
\hline $1 \mathrm{AE}$ & 2,83 & 2,95 & 5,45 & 3,58 & 4,81 & 7,11 & 2,66 & 6,24 & 5,42 & 5,91 & 3,31 & 4,07 & 3,96 \\
\hline $1 \mathrm{DE}$ & 3,07 & 3,02 & 5,51 & 3,81 & 5,03 & 6,04 & 2,5 & 5,61 & 5,48 & 5,87 & 3,45 & 4,25 & 3,26 \\
\hline $3 D E$ & 3,24 & 3,1 & 4,93 & 3,94 & 4,52 & 5,97 & 2,63 & 5,59 & 4,89 & 4,51 & 3,85 & 4,12 & 2,57 \\
\hline $5 \mathrm{DE}$ & 3,4 & 3,12 & 4,96 & 3,99 & 5,13 & 6,06 & 2,78 & 4,74 & 5,19 & 4,14 & 4,1 & 4,52 & 2,8 \\
\hline 9DE & 3,83 & 3,24 & 5,61 & 3,73 & 5,53 & 5,43 & 3,11 & 3,4 & 5,5 & 4,04 & 4,49 & 5,01 & 3,2 \\
\hline $\begin{array}{l}\text { 11DE/2D } \\
\mathrm{T}\end{array}$ & 4,05 & 3,31 & 5,94 & 4,01 & 6,01 & 5,53 & 3,37 & 4,3 & 5,29 & 4,26 & 4,85 & 5,51 & 3,41 \\
\hline $\begin{array}{l}19 \mathrm{AE} / 10 \\
\text { AT }\end{array}$ & 4,84 & 3 & 6,08 & 4,89 & 7,13 & 6,09 & 2,8 & 4,1 & 5,95 & 4,51 & 6,55 & 5,61 & 3,25 \\
\hline $\begin{array}{l}\text { 26DE/17 } \\
\text { AT }\end{array}$ & 5,04 & 2,34 & 6,81 & 4,68 & 7,14 & 5,69 & 3,13 & 3,41 & 6,58 & 4,48 & 7,58 & 7,64 & 3,73 \\
\hline Tempo & & & & & & & & & & & & & \\
\hline
\end{tabular}




\begin{tabular}{|l|l|l|l|l|l|l|l|l|l|l|l|l|l|}
\hline & $\geq 50$ & $\geq 50$ & $\geq 50$ & $\geq 50$ & $\geq 50$ & $\geq 50$ & $\geq 50$ & $\geq 50$ & $\geq 50$ & $\geq 50$ & $\geq 50$ & $\geq 50$ & $\geq 50$ \\
\hline $1 \mathrm{AE}$ & 25,51 & 7,52 & 11,94 & 12,35 & 15,35 & 12,83 & 4,45 & 12 & 6,33 & 7,64 & 6,14 & 10,28 & 3,72 \\
\hline $1 \mathrm{DE}$ & 25,64 & 7,56 & 12,36 & 12,56 & 15,44 & 12,94 & 4,46 & 13,13 & 6,5 & 7,83 & 6,42 & 10,58 & 4,75 \\
\hline $3 \mathrm{DE}$ & 26,08 & 7,62 & 12,58 & 12,98 & 16,58 & 13,41 & 4,43 & 13,83 & 7,75 & 10,16 & 6,88 & 10,74 & 5,84 \\
\hline $5 \mathrm{DE}$ & 26,25 & 7,73 & 12,76 & 13,63 & 16,79 & 10,61 & 4,43 & 8,25 & 8,12 & 8,75 & 7,37 & 9,87 & 6,03 \\
\hline 9DE & 26,79 & 7,97 & 12,99 & 14,35 & 18,22 & 11,87 & 4,47 & 10,95 & 8,59 & 10,55 & 7,97 & 10,17 & 6,28 \\
\hline $\begin{array}{l}11 \mathrm{DE} / 2 \mathrm{D} \\
\mathrm{T}\end{array}$ & 27,4 & 8,11 & 13,13 & 9,22 & 16,87 & 12,11 & 4,49 & 10,32 & 8,9 & 11,06 & 8,51 & 6,01 & 6,39 \\
\hline $\begin{array}{l}19 \mathrm{AE} / 10 \\
\text { AT }\end{array}$ & 22,79 & 9,63 & 13,72 & 9,63 & 11,41 & 13,21 & 1,39 & 13 & 9,95 & 12,75 & 4,12 & 8,85 & 7,78 \\
\hline $\begin{array}{l}26 \mathrm{DE} / 17 \\
\text { AT }\end{array}$ & 14,71 & 9,48 & 8,54 & 7,66 & 14,68 & 17,33 & 1,39 & 13,52 & 10,38 & 14,97 & 5,34 & 5,21 & 8,04 \\
\hline
\end{tabular}

Para o quinto grupo (Tabela 15), todas as árvores comerciais dos tratamentos silviculturais na primeira classe diamétrica recuperou o volume, já para a segunda classe diamétrica, os tratamentos T1, T4, T5, T7, T8, T9, T10 e T12 recuperaram o seu volume de antes da exploração.

Tabela 15: Volume de madeira $\left(\mathrm{m}^{3} / \mathrm{ha}\right)$ do grupo $\mathrm{G} 5$ nos tratamentos silviculturais por classe diamétrica na Companha Monte Dourado-Jari, Amapá.

\begin{tabular}{|c|c|c|c|c|c|c|c|c|c|c|c|c|c|}
\hline & T0 & $\mathrm{T} 1$ & $\mathrm{~T} 2$ & T3 & $\mathrm{T} 4$ & T5 & T6 & T7 & T8 & T9 & T10 & T11 & T12 \\
\hline \multicolumn{14}{|l|}{ Tempo } \\
\hline & $\begin{array}{l}20- \\
49,9 \\
\end{array}$ & $\begin{array}{l}20- \\
49,9\end{array}$ & $\begin{array}{l}20- \\
49,9\end{array}$ & $\begin{array}{l}20- \\
49,9\end{array}$ & $\begin{array}{l}20- \\
49,9\end{array}$ & $\begin{array}{l}20- \\
49,9\end{array}$ & $\begin{array}{l}20- \\
49,9\end{array}$ & $\begin{array}{l}20- \\
49,9\end{array}$ & $\begin{array}{l}20- \\
49,9\end{array}$ & $\begin{array}{l}20- \\
49,9\end{array}$ & $\begin{array}{l}20- \\
49,9\end{array}$ & $\begin{array}{l}20- \\
49,9\end{array}$ & $\begin{array}{l}20- \\
49,9\end{array}$ \\
\hline $1 \mathrm{AE}$ & 27,95 & 27,38 & 25,72 & 16,31 & 26,75 & 27,93 & 20,78 & 27,89 & 27,24 & 23,58 & 20,9 & 32,14 & 23,34 \\
\hline $1 \mathrm{DE}$ & 28,7 & 26,73 & 26,33 & 16,95 & 26 & 24,95 & 21,36 & 27,26 & 25,07 & 23,41 & 19,2 & 31,56 & 20,77 \\
\hline $3 D E$ & 29,78 & 27,03 & 26,4 & 17,68 & 25,68 & 24,52 & 23,86 & 27,79 & 24,89 & 22,71 & 19,06 & 30,27 & 19,83 \\
\hline $5 \mathrm{DE}$ & 30,42 & 27,76 & 26,97 & 18,43 & 26,65 & 24,79 & 24,95 & 27,42 & 26,96 & 23,93 & 19,9 & 32,32 & 21,08 \\
\hline 9DE & 32,41 & 29,65 & 29,03 & 19,01 & 27,95 & 27,65 & 27,71 & 27,87 & 30,11 & 25,93 & 22,68 & 33,66 & 23,89 \\
\hline $\begin{array}{l}\text { 11DE/2D } \\
T\end{array}$ & 33,48 & 29,42 & 26,8 & 16,72 & 27,76 & 28,3 & 25,73 & 25,02 & 31,63 & 27,64 & 25,65 & 28,86 & 23,72 \\
\hline $\begin{array}{l}\text { 19AE/10 } \\
\text { AT }\end{array}$ & 32,16 & 31,97 & 29,56 & 22,59 & 31,09 & 33, & 28,6 & 28,14 & 34,58 & 32,72 & 34,01 & 35,1 & 30,35 \\
\hline $\begin{array}{l}\text { 26DE/17 } \\
\text { AT }\end{array}$ & 35,49 & 32,84 & 32,85 & 21,43 & 33,89 & 31,7 & 32,52 & 30,12 & 39,18 & 34,21 & 40,83 & 43,59 & 30,1 \\
\hline \multicolumn{14}{|l|}{ Tempo } \\
\hline & $\geq 50$ & $\geq 50$ & $\geq 50$ & $\geq 50$ & $\geq 50$ & $\geq 50$ & $\geq 50$ & $\geq 50$ & $\geq 50$ & $\geq 50$ & $\geq 50$ & $\geq 50$ & $\geq 50$ \\
\hline $1 \mathrm{AE}$ & 63,45 & 34,86 & 31,87 & 25,26 & 33,8 & 37,45 & 25,89 & 45,9 & 26,8 & 38,43 & 31,21 & 43,36 & 19,3 \\
\hline $1 \mathrm{DE}$ & 64,27 & 33,75 & 28,63 & 25,54 & 35,18 & 35,68 & 24,9 & 45,02 & 26,12 & 37,53 & 31,89 & 42,44 & 22,82 \\
\hline $3 D E$ & 65,44 & 27,88 & 23,08 & 24,81 & 38,06 & 36,67 & 21,41 & 46,13 & 26,75 & 40,52 & 33,51 & 45,6 & 24,43 \\
\hline $5 \mathrm{DE}$ & 60,41 & 27,41 & 24,48 & 21,48 & 37,49 & 30,66 & 22 & 40,73 & 27,42 & 39,89 & 35,47 & 37,05 & 23,41 \\
\hline 9DE & 60,71 & 31,22 & 25,39 & 22,54 & 41,31 & 34,08 & 21,66 & 45,54 & 26,89 & 38,53 & 39,62 & 42,25 & 24,92 \\
\hline $\begin{array}{l}\text { 11DE/2D } \\
T\end{array}$ & 58,28 & 32,02 & 24,72 & 17,46 & 39,29 & 33,62 & 20,98 & 39,38 & 26,23 & 34,64 & 41,07 & 37,67 & 25,04 \\
\hline $\begin{array}{l}\text { 19AE/10 } \\
\text { AT }\end{array}$ & 51,25 & 35,03 & 27,64 & 18,37 & 34,46 & 31,35 & 20,61 & 43,07 & 31,05 & 40,11 & 41,1 & 40,39 & 27,62 \\
\hline $\begin{array}{l}\text { 26DE/17 } \\
\text { AT }\end{array}$ & 39,8 & 37,11 & 20,19 & 18,6 & 41,17 & 40,31 & 24,77 & 48,19 & 34,77 & 44,56 & 46,21 & 36,78 & 26,73 \\
\hline
\end{tabular}

\section{Floresta do Moju}

Nessa área foi observado que para todos os grupos e em todas as classes diamétricas tiveram êxito em sua resiliência 13 e 18 anos após a exploração florestal, somente as árvores da segunda classe diamétrica do primeiro grupo de árvores não recuperaram o seu volume de madeira (Tabela 16).

Tabela 16: Volume de madeira $\left(\mathrm{m}^{3} / \mathrm{ha}\right)$ em todos os grupos por classe diamétrica na Floresta Moju, Pará.

\begin{tabular}{|l|l|l|l|l|l|l|l|l|l|l|}
\hline Grupo & G1 & G1 & G2 & G2 & G3 & G3 & G4 & G4 & G5 & G5 \\
\hline Tempo & & & & & & & & & & \\
\hline & $20-49,9$ & $\geq 50$ & $20-49,9$ & $\geq 50$ & $20-49,9$ & $\geq 50$ & $20-49,9$ & $\geq 50$ & $20-49,9$ & $\geq 50$ \\
\hline $2 \mathrm{AE}$ & 11,54 & 42,67 & 43,65 & 40,24 & 73,41 & 72,84 & 37,01 & 16,92 & 62,99 & 34,78 \\
\hline
\end{tabular}




\begin{tabular}{|l|l|l|l|l|l|l|l|l|l|l|}
\hline $1 \mathrm{DE}$ & 10,63 & 25,88 & 43,68 & 33,19 & 75,71 & 59,9 & 37,55 & 16,5 & 65,85 & 35,12 \\
\hline $13 \mathrm{DE}$ & 12,57 & 31,37 & 45,73 & 41,41 & 84,45 & 76,02 & 38,2 & 20,85 & 72,7 & 45,87 \\
\hline $18 \mathrm{DE}$ & 12,91 & 34,06 & 44,93 & 47,44 & 87,03 & 87,78 & 37,42 & 25,74 & 74,94 & 54,98 \\
\hline
\end{tabular}

\section{Fazenda Rio Capim}

Para o primeiro grupo de árvores (G1) após 8 anos de exploração, somente o tratamento T0 aumentou o valor do seu volume de madeira para as duas classes diamétricas (Tabela 17).

Tabela 17: Volume de madeira ( $\mathrm{m}^{3} / \mathrm{ha}$ ) no G1 nos tratamentos silviculturais por classe diamétrica na Fazenda Rio Capim, Pará.

\begin{tabular}{|l|l|l|l|l|l|l|}
\hline & T0 & T1 & T2 & T0 & T1 & T2 \\
\hline Tempo & & & & & & \\
\hline & $20-49,9$ & $20-49,9$ & $20-49,9$ & $\geq 50$ & $\geq 50$ & $\geq 50$ \\
\hline AE & 5,72 & 5,75 & 4,73 & 25,62 & 58,3 & 68,6 \\
\hline $1 D E$ & 5,84 & 4,69 & 4,81 & 25,86 & 37,6 & 32,44 \\
\hline $2 D E$ & 6,05 & 4,77 & 4,64 & 25,19 & 37,96 & 33,2 \\
\hline $4 D E$ & 6,43 & 5,03 & 4,66 & 25,19 & 29,51 & 34,75 \\
\hline $5 D E$ & 6,54 & 5,22 & 4,14 & 25,69 & 30,39 & 34,76 \\
\hline $8 D E$ & 7,08 & 5,53 & 4,37 & 25,63 & 30,62 & 35,25 \\
\hline
\end{tabular}

Para o segundo grupo (Tabela 18), somente o tratamento T0 aumentou e manteve o seu volume de madeira nas duas classes diamétricas após oito anos de exploração florestal.

Tabela 18: Volume de madeira $\left(\mathrm{m}^{3} / \mathrm{ha}\right)$ no grupo $\mathrm{G} 2$ nos tratamentos silviculturais por classe diamétrica na Fazenda Rio Capim, Pará.

\begin{tabular}{|l|l|l|l|l|l|l|}
\hline & T0 & T1 & T2 & T0 & T1 & T2 \\
\hline Tempo & & & & & & \\
\hline & $20-49,9$ & $20-49,9$ & $20-49,9$ & $\geq 50$ & $\geq 50$ & $\geq 50$ \\
\hline AE & 34,85 & 31,23 & 33,51 & 57,41 & 78,64 & 78,68 \\
\hline $1 D E$ & 35,25 & 28,06 & 33,37 & 58,78 & 60,71 & 48,08 \\
\hline $2 D E$ & 35,71 & 27,76 & 32,98 & 58,7 & 62,17 & 47,24 \\
\hline $4 D E$ & 36,52 & 29,26 & 34,32 & 58,14 & 58,52 & 49,01 \\
\hline $5 D E$ & 37,64 & 28,92 & 33,42 & 58,75 & 59,52 & 50,18 \\
\hline $8 D E$ & 40,34 & 30,75 & 32,72 & 57,4 & 61,59 & 50,59 \\
\hline
\end{tabular}

Para o terceiro grupo (Tabela 19), as árvores da classe diamétrica $20-49,9 \mathrm{~cm}$ todos os tratamentos recuperaram o seu volume após 8 anos da exploração florestal, porém os indivíduos da classe diamétrica $\geq$ $50 \mathrm{~cm}$, nenhum dos tratamentos silviculturais recuperaram o seu volume inicial.

Tabela 19: Volume de madeira ( $\mathrm{m}^{3} / \mathrm{ha}$ ) no G3 nos tratamentos silviculturais por classe diamétrica na Fazenda Rio Capim, Pará.

\begin{tabular}{|l|l|l|l|l|l|l|}
\hline & T0 & T1 & T2 & T0 & T1 & T2 \\
\hline Tempo & & & & & & $\geq 50$ \\
\hline & $20-49,9$ & $20-49,9$ & $20-49,9$ & $\geq 50$ & $\geq 50$ & 114,28 \\
\hline AE & 69,49 & 74,48 & 71,24 & 87,34 & 101,34 & 72,92 \\
\hline $1 D E$ & 70,26 & 71,64 & 71,93 & 88,51 & 81,76 & 72,87 \\
\hline $2 D E$ & 70,94 & 70,82 & 72,31 & 87,73 & 83,48 & 74,97 \\
\hline $4 D E$ & 71,56 & 73,72 & 76,44 & 87,64 & 77,05 & 76,33 \\
\hline $5 D E$ & 73,48 & 74,29 & 76,2 & 88,83 & 78,52 & 74,6 \\
\hline $8 D E$ & 76,44 & 77,5 & 74,47 & 86,93 & 82,44 & \\
\hline
\end{tabular}

Para o quarto grupo (Tabela 20), todos os tratamentos tiveram resiliência para as duas classes diamétricas, após 8 anos de exploração florestal. 
Tabela 20: Volume de madeira ( $\mathrm{m}^{3} / \mathrm{ha}$ ) no G4 nos tratamentos silviculturais por classe diamétrica na Fazenda Rio Capim, Pará.

\begin{tabular}{|l|l|l|l|l|l|l|}
\hline & T0 & T1 & T2 & T0 & T1 & T2 \\
\hline Tempo & & & & & & $\geq$ \\
\hline & $20-49,9$ & $20-49,9$ & $20-49,9$ & $\geq 50$ & $\geq 50$ & $\geq 50$ \\
\hline AE & 30,75 & 26,51 & 30,83 & 41,53 & 33,9 & 31,24 \\
\hline $2 \mathrm{DE}$ & 31,08 & 24,36 & 30,66 & 42,8 & 33,27 & 31,72 \\
\hline $4 \mathrm{DE}$ & 31,44 & 24,01 & 30,49 & 42,56 & 34,45 & 30,77 \\
\hline $5 \mathrm{DE}$ & 31,97 & 25,4 & 31,94 & 42,42 & 35,69 & 32,16 \\
\hline $8 \mathrm{DE}$ & 33,01 & 25,01 & 31,72 & 42,78 & 36,15 & 33,29 \\
\hline
\end{tabular}

Para o quinto grupo (Tabela 21), os indivíduos classe diamétrica $20-49,9 \mathrm{~cm}$, todos os tratamentos silviculturais recuperaram o seu volume inicial. E para os indivíduos classe diamétrica $\geq 50 \mathrm{~cm}$ somente o T1 recuperou o seu volume.

Tabela 21: Volume de madeira ( $\mathrm{m}^{3} / \mathrm{ha}$ ) no G5 nos tratamentos silviculturais por classe diamétrica na Fazenda Rio Capim, Pará.

\begin{tabular}{|l|l|l|l|l|l|l|}
\hline & T0 & T1 & T2 & T0 & T1 & T2 \\
\hline Tempo & & & & & & \\
\hline & $20-49,9$ & $20-49,9$ & $20-49,9$ & $\geq 50$ & $\geq 50$ & $\geq 50$ \\
\hline AE & 65,07 & 69,63 & 68,34 & 63,85 & 44,56 & 50,37 \\
\hline $1 \mathrm{DE}$ & 65,77 & 67,8 & 68,98 & 64,8 & 44,16 & 43,35 \\
\hline $2 \mathrm{DE}$ & 66,23 & 66,92 & 69,56 & 63,8 & 45,52 & 42,48 \\
\hline $4 \mathrm{DE}$ & 66,51 & 69,68 & 73,75 & 63,72 & 47,54 & 43,04 \\
\hline $5 \mathrm{DE}$ & 68,34 & 70,18 & 74,08 & 64,42 & 48,13 & 44,23 \\
\hline $8 \mathrm{DE}$ & 70,78 & 73,2 & 72,23 & 62,59 & 51,83 & 42,08 \\
\hline
\end{tabular}

\section{DISCUSSÃO}

Observou-se que, para os grupos em que há espécies exploradas os tratamentos não tiveram resiliência, enquanto que, nos grupos em que não se contabilizava o volume das espécies exploradas, houve resiliência florestal volumétrica na maioria dos tratamentos. Para a classe diamétrica de $20-49,99 \mathrm{~cm}$, a exploração florestal não afeta a resiliência quanto ao volume de madeira no decorrer do tempo, sendo evidente que para os grupos que envolviam um maior número de espécies a recuperação foi maior.

Para os grupos em que, as espécies que foram exploradas são poupadas ou excluídas da análise, o número de tratamentos que recuperou o volume de madeira foi bem maior que em todos os outros grupos principalmente para a segunda classe diamétrica, que serão as espécies indicadas para serem exploradas no segundo ciclo de corte.

Há poucos trabalhos sobre estoque de volume de madeira na Amazônia (HIGUCHI, 2015). Prance et al. (1976) realizou um inventário florestal em um hectare (ha) de floresta e constatou que o estoque de volume de madeira aproveitável, de árvores com DAP $\geq 15 \mathrm{~cm}$, era de $286,4 \mathrm{~m}^{3}$. D'Oliveira et al. (2006) apresentaram uma estimativa média para uma área localizada no estado do Acre. De acordo com os autores, o estoque de volume total, considerando árvores com DAP $\geq 10 \mathrm{~cm}$, foi estimado em $180 \mathrm{~m}^{3}$.ha- ${ }^{1}$, sendo que $42 \mathrm{~m}^{3} \cdot$ ha- $^{1}$ é o estoque estimado para o grupo de espécies comerciais e destas apenas $20 \mathrm{~m}^{3}$.ha- ${ }^{1}$ de indivíduos com DAP $\geq 50 \mathrm{~cm}$. De acordo com Higuchi et al. (1985), os primeiros trabalhos de ajuste de equações de volume publicados na Amazônia foram realizados na região Oriental.

Em um estudo realizado por Higuchi (2015) em onze localidades distintas (ocasionalmente também 
chamadas de 'Sítio'), distribuídas em 12 municípios diferentes, localizados em sete sub-regiões do estado do Amazonas (AM), sobre Dinâmica de volume e biomassa da floresta de terra firme do Amazonas, a estimativa média do estoque de madeira cai ainda mais quando o mesmo é compartimentado por classe diamétrica 'comercial'. Esta divisão é dada em função do diâmetro mínimo de corte estabelecido pela legislação vigente, sendo: 'regeneração natural - RN' $(10,0 \leq \mathrm{DAP}<30,0 \mathrm{~cm})$; 'estoque futuro - EF' $(30,0 \leq \mathrm{DAP}<50,0 \mathrm{~cm}) \mathrm{e}$ 'estoque atual - EA' (DAP $\geq 50,0 \mathrm{~cm}$ ). No presente estudo das quatro áreas as espécies arbóreas comercias foram separadas e analisadas em duas classes de diâmetro de 20-49,9 cm e $\geq 50 \mathrm{~cm}$ antes e após a exploração florestal de impacto reduzido.

Segundo D'Oliveria et al. (2006), o estoque de volume de uma floresta depois de uma exploração seletiva, no Acre, em 180,0 $\mathrm{m}^{3}$.ha- ${ }^{-1}$ (árvores vivas, DAP $\geq 10 \mathrm{~cm}$ ). Árvores ocas, bifurcadas ou com tronco muito tortuoso geralmente não são aproveitadas pela indústria madeireira, devido ao baixo nível tecnológico e valor da madeira. A topografia influencia na exploração propriamente dita, pois a madeira pode estar localizada em um ponto de acesso limitado, impedindo a mecanização do processo. Portanto, é muito provável que a média do volume disponível para exploração seja inferior à estimada (HIGUCHI, 2015).

A classe DAP $\geq 50 \mathrm{~cm}$, apesar de participar com boa parte dos estoques de área basal e volume, ainda não consolidam uma 'posição de dominância'. Analisando os resultados da distribuição diamétrica novamente, considerando um DAP mínimo de $5 \mathrm{~cm}$, constata-se que as três primeiras classes $(5$ à $10 \mathrm{~cm} ; 10$ à $20 \mathrm{~cm} ; 20$ à $30 \mathrm{~cm})$ correspondem à $91, \%( \pm 2,5 \%)$ do total dos indivíduos por hectare. O volume, estas classes correspondem à $37,8 \%$ do estoque total. Assim, os outros $10 \%$ das árvores (DAP $\geq 30,0$ ) representam mais da metade das estimativas médias por unidade de área, em volume, com 62,2\% (HIGUCHI, 2015).

\section{CONCLUSÕES}

O volume de madeira de espécies arbóreas comercias encontrados nas áreas de estudo foram dinâmicos e diferentes nos tratamentos silviculturais, classe diamétricas, tempo e em cada grupo. É possível afirmar que a floresta é capaz de ter sua resiliência volumétrica, pois observou-se nessas áreas de estudos que a maioria das espécies arbóreas comerciais nos diferentes tratamentos silviculturais aumentaram seu volume após 30, 26 e 18 anos de exploração florestal de impacto reduzido. A resiliência florestal em termos de volume de madeira é maior para os grupos em que exclui-se as espécies que foram exploradas, para as duas classes diamétricas.

AGRADECIMENTOS: a Universidade Federal Rural da Amazônia-UFRA, a Embrapa Amazônia Oriental, a Capes, ao CNPQ, aos Pesquisadores, Técnicos e estudantes que de alguma maneira contribuíram para a obtenção desse trabalho.

\section{REFERÊNCIAS}

ALVARES, C. A.; STAPE, J. L.; SENTELHAS, P. C.; GONÇALVES, J. L. M.. Modeling monthly mean air temperature for Brazil. Theoretical and Applied Climatology, v.113, n.3-4, p.407-
427, 2013.

BAIMA, A. V.; SILVA, S. M. S.; SILVA, J. N. M.. Equações de 
volume para floresta tropical de terra firme em Moju, PA. In: SILVA, J. N. M.; CARVALHO, J. O. P.; YARED, J. A. G.. A Silvicultura na Amazônia Oriental: contribuições do projeto silvicultura tropical (Embrapa/DFID). 2 ed. Belém: Embrapa Amazônia Oriental, 2001. p.367-392.

CARVALHO, J. O. P. ; SILVA, J. N. M.; LOPES, J. C. A.. Growth rate of a terra firmed rain forest in Brazilian Amazonia over an eight-year period in response to logging. Acta Amazônica, Manaus, v.34, n.2, p.209-217, 2004.

CASTRO, T. C. ; CARVALHO, J. O. P.. Dinâmica da população de Manilkara huberi (Ducke) A. Chev. durante 26 anos após a exploração florestal em uma área de terra firme na Amazônia brasileira. Ciência Florestal, v.24, p.161-169, 2014.

D'OLIVEIRA, M. V. N.; BRAZ, E. M.. Estudo da dinâmica da floresta manejada no projeto de manejo florestal comunitário do PC Pedro Peixoto na Amazônia Ocidental. Acta Amazônia, v.36, n.2, p.177-182, 2006.

FRANCEZ, L. M. B.; CARVALHO, J. O. P.; BATISTA, F. J.; JARDIM, F. C. S.; RAMOS, E. M. L. S.. Influência da exploração florestal de impacto reduzido sobre as fases de desenvolvimento de uma floresta de terra firme, Pará, Brasil. Ciência Florestal, v.23, p.743-753, 2013.

HIGUCHI, F. G.. Dinâmica de volume e biomassa da floresta de terra firme do Amazonas. Tese (Doutorado) Universidade Federal do Paraná, Curitiba, 2015.

HIGUCHI, N.; RAMM, W.. Developing bole wood volume equations for a group of tree species of Central Amazon (Brazil). Commonw. For. Rev., v.64, n.1, p.33-41, 1985.

HIRAMATSU, N. A.. Equações de volume comercial para espécies nativas na região do Vale do Jari, Amazônia Oriental. Dissertação (Mestrado) - Universidade Federal do Paraná, Curitiba, 2008.

IVANAUSKAS, N. M.; ASSIS, M. C.. Formações florestais brasileiras. In: MARTINS, S. V.. Ecologia de florestas tropicais do Brasil. 2 ed. Viçosa: Universidade Federal de Viçosa, 2012. p.252-293.

LOPES, J. C. A.; WHITMORE, T. C.; BROWN, N. D.; JENNINGS, S. B.. Banco de sementes de uma floresta tropical úmida no município de Moju, PA. In: SILVA, J. N. M.; CARVALHO, J. O. P.; YARED, J. A. G.. A Silvicultura na Amazônia Oriental: contribuições do projeto silvicultura tropical (Embrapa/DFID). 2 ed. Belém: Embrapa Amazônia Oriental, 2001. p.367-392.

OLIVEIRA, L. C.. Efeito da exploração da madeira e de diferentes intensidades de desbastes sobre a dinâmica da vegetação de uma área de 136 ha na floresta nacional do
Tapajós. Tese (Doutorado em Recursos Florestais) Universidade de São Paulo, Piracicaba, 2005.

PARÁ. Secretaria de Estado de Meio Ambiente. Extração e movimentações de toras de madeira nativa por município com classificação por espécie vegetal, indicando a quantidade de cargas, o volume em metros cúbicos e o valor comercializado: Relatório engloba o periodo de 01/01/2006 até 21/02/2016. Bélem: SEMA, 2016.

PRANCE, G. T.; RODRIGUES, W. A.; SILVA, M. F.. Inventário florestal de um hectare de mata de terra firme $\mathrm{km} 30 \mathrm{da}$ Estrada Manaus - Itacoatiara. Acta Amazônica, v.6, n.1, p.935, 1976 .

IBGE. Instituto Brasileiro de Geografia e Estatística. Procedimentos para mapeamentos Brasil ISSN 0103-9598 Manuais técnicos em geociências Divulga os procedimentos metodológicos utilizados nos estudos e pesquisas de geociências. Rio de Janeiro: IBGE, 2012.

RÊGO, A. B. M. L.; SOUZA, P. B.; SILVA, R. R.; RÊGO, P. L.. Composição florística e estrutural de um componente. In: SCHMIDER, E.; ZIEGLER, M.; DANAY, E.; BEYER, L.; BUHNER, M.. Is it really robust? Reinvestigating the robustness of ANOVA against the normal distribution assumption. Methodology, v.6, n.4, p.15-147, 2015.

SILVA, E. J. V.. Dinâmica de florestas manejadas e sob exploração convencional na Amazônia oriental - São Carlos. Tese (Doutorado) - Universidade de São Paulo, 2004.

SILVA, J. N. M.; CARVALHO, J. O. P.; LOPES, J. C. A.; ALMEIDA, B. F.; COSTA, D. H. M.; OLIVEIRA, L. C.; VANCLAY, J. K.; SKOVSGAARD, J. P.. Growth and yield of a tropical rain forest of the Brazilian Amazon 13 years after logging. Forest Ecology and Management, Amsterdã, n.71, p.267-274, 1995.

SILVA, J. N. M.; ARAÚJO, S. M. A.. Equação de volume para árvores de pequeno diâmetro na Floresta Nacional do Tapajós. Boletim de Pesquisa Florestal, v.8/9, p.16-25, 1984a.

SILVA, J. N. M.; CARVALHO, M. S. P.. Equações de volume para uma floresta secundária no planalto do Tapajós, Belterra/Pará. Boletim de Pesquisa Florestal, v.8/9, p.1-15, 1984b.

SILVA, S. M. A.; SILVA, J. N. M.; BAIMA, A. M. V.; LOBATO, N. M.; THOMPSON, I. S.; COSTA FILHO, P. P.. Impacto da exploração madeireira em floresta de terra firme no município de Moju, Estado do Pará. In: SILVA, J. N. M.; CARVALHO, J. O. P.; YARED, J. A. G.. A silvicultura na Amazônia Oriental: Contribuições do projeto Embrapa-DFID. Belém: Embrapa Amazônia Oriental, 2001. p.309-323.

A CBPC - Companhia Brasileira de Produção Científica (CNPJ: 11.221.422/0001-03) detém os direitos materiais desta publicação. Os direitos referem-se à publicação do trabalho em qualquer parte do mundo, incluindo os direitos às renovações, expansões e disseminações da contribuição, bem como outros direitos subsidiários. Todos os trabalhos publicados eletronicamente poderão posteriormente ser publicados em coletâneas impressas sob coordenação da Sustenere Publishing, da Companhia Brasileira de Produção Científica e seus parceiros autorizados. Os (as) autores (as) preservam os direitos autorais, mas não têm permissão para a publicação da contribuição em outro meio, impresso ou digital, em português ou em tradução. 